\title{
Missing Subjects in Early Child Language
}

\author{
Nina Hyams
}

\section{Language Acquisition and Linguistic Theory}

The marriage of linguistic theory and language acquisition is approaching its golden anniversary. In her 1966 dissertation Ursula Bellugi provided a transformational analysis of the development of negation in English-speaking children. On the model of the Standard Theory of Generative Grammar (Chomsky 1965), she proposed a system of phrase structure and transformational rules to describe the various stages of negation and the transitions from one stage to the next. Following Bellugi's seminal work, various studies provided transformational analyses of other aspects of child grammar (Bloom 1970; Klima and Bellugi 1966; Brown and Fraser 1964; Brown et al. 1964; Brown 1973 among others). In keeping with the goals of generative grammar, these studies attempted to provide an explicit procedure for generating all and only the utterances produced by children in a specific age range or with respect to a specific aspect of grammar. While acknowledging that children's early utterances were more or less reduced versions of the adult target - "telegraphic" as characterized by Brown and Fraser (1964) — the descriptive focus was on the categories and combinations that the child reliably produced, rather than what he failed to produce or produced only probabilistically.

Fast forward 20 some odd years, it had become increasingly apparent that the "telegraphic" child's two and three word utterances belie a far richer and more abstract grammatical system. His language shows grammatical dependencies such as agreement (Hyams 1983, 1986; Guasti 1993/1994; Poeppel and Wexler 1993), case (Babyonyshev 1993; Schütze 1996), and verb movement (Pierce 1992; Verrips and Weissenborn 1992 among others), hence a sensitivity to the grammatical function of nouns and to the tense and aspect of verbs. The focus of generative acquisition research into early development shifted from the description of what

\footnotetext{
N. Hyams $(\square)$

Linguistics Department, UCLA, 3125 Campbell Hall, Los Angeles, CA 90095-1543, USA

e-mail: hyams@humnet.ucla.edu
} 
children produce to investigation of what they seem to know, but fail to systematically produce. This includes, in particular, the various missing elements that give early language its telegraphic look - dropped pronouns, auxiliaries, inflections, determiners, and the functional architecture that supports these elements.

Much of the shift in focus was prompted by the publication of Chomsky's Lectures on Government and Binding (LGB) (1982). The principles and parameters model of Universal Grammar (UG) outlined in LGB ushered in a new era of syntactic research, but also a renewed interest and excitement in childhood grammatical development. The view of grammar acquisition as a system of parameter setting seemed ideally suited to address the logical problem of language acquisition - how human speakers come to know as much as we do based on limited language experience. The parameters more clearly defined the boundary conditions on the child's task - to choose among competing values (ideally binary) along an array of parameters. They also offered a new perspective on the role that input plays in the acquisition process, viz. the primary linguistic data act as "triggers" to set each parameter at one or another of its predetermined values. On this view, much of the child's linguistic knowledge is "imprinted" rather than learned in the classical sense.

Parameter theory also provided a more tractable framework for understanding and describing grammatical development - the temporal unfolding of language in the child. Within this framework, what we descriptively refer to as a "stage" represents the instantiation of a particular parameter value (or values), either correct or incorrect vis-à-vis the target grammar. If incorrect, the parameter must be reset at some point on the basis of relevant input data, and this resetting would give rise to a new "stage" or grammar. Conceived in this way, each stage in the acquisition sequence is constrained by the parameter space of UG much in the way we understand grammatical variation across adult languages to be so constrained.

Parameter theory thus offers not only a model of how language acquisition could proceed in principle under the boundary conditions set by an impoverished linguistic environment (impoverished with respect to abstract linguistic rules and representations) and UG, it also provides a model of how development proceeds in fact. It is fair to say that parameter theory considerably broadened the application and explanatory potential of linguistic theory to acquisition research. As example, the development of children's negative sentences from an external Neg element (No the sun shining) to a clause internal position (The sun not shining), as posited by Bellugi, was reformulated by Pierce (1992) as movement of the verb from its base-generated VP internal position to a higher functional head (INFL) over negation, a rule not specifically designed to capture a shift in the child's language, but a well-worn rule of many adult languages, a parametric option of UG. ${ }^{1}$

Among the abstract elements in child language that received heightened attention post-LGB were missing subjects in non-null subject languages such as English, illustrated in (1)-(3) below. Earlier studies had remarked upon missing subjects

\footnotetext{
${ }^{1}$ But see Stromswold (1990) and Drozd (1995) for criticism of the parameter-setting model of "external negation."
} 
(e.g. Greenfield and Smith 1976), but it is fair to say that missing subjects were not a central area of research.

In this paper I will discuss early grammatical development through the prism of missing subjects in child language. I will review some of the central work on this topic, and attempt to draw out the more general implications of missing subjects for parameter-setting models of development and maturational models. I will also discuss more recent analytical directions, which focus on the informational context of missing subjects. I begin by discussing grammatical approaches to missing subjects, including parameter setting and maturational analyses (Sect. 2). I then turn to performance-based accounts (Sect. 3), especially those that focus on production constraints in young children. The review of findings from spontaneous production and imitation studies leads to a discussion of the converging results of the different methodologies used to explore null subjects in early language. In this context, I present the results of a recent comprehension study on null subjects in English (Orfitelli 2008; Orfitelli and Hyams 2008, 2010) and the implications of those results for competence and performance models (Sect. 4). Finally, I discuss some recent (and not so recent) findings illustrating children's pragmatic knowledge in choosing specific subject types (null, pronominal, lexical), how early sensitivity to information structure (IS) interacts with grammatical knowledge (and potentially production output), and how pragmatic principles may in fact account for certain results that have thus far been attributed to processing limitations in early language.

\section{Missing Subjects and Parameter Missettings}

Once we assume that UG consists of a system of parameters and that the child's task is to set these parameters at the appropriate values for the target language, it is a small step to imagine that children could misset these parameters, or that the parameters might come preset at a universal value, correct for some languages, but not for others. The parameter missetting hypothesis provides a framework to directly address the question of why the child makes certain "errors" but not others, and shows a particular developmental sequence rather than another logically possible one.

\subsection{The Pro-drop Hypothesis}

The parameter missetting idea was developed in Hyams (1983, 1986), where I argued that children's missing subjects are the result of a positive setting along the pro-drop (or null subject) parameter, the parameter responsible for licensing null subjects by "rich" inflection in languages like Italian and Spanish. The subject drop phenomenon is illustrated in (1)-(3) in English, French and Danish, languages that 
do not license null subjects in their adult version, the examples in (1) are from Bloom et al. (1975a, b) and Brown (1973); the Danish and French examples, in (2) and (3) respectively, are from Hamann and Plunkett (1998).

(1) a. Want more apple.

b. Tickles me.

c. No play matches.

d. Show Mommy that.

(2) a. Ikke kore traktor.

Not drive tractor

'(I, you, he) doesn't drive the tractor.'

b. Se, blomster har.

Look, flowers have.

'Look, (I, you, he, she, etc.) have/s flowers.'

(3) a. A tout tout tout mangé

has all all all eaten

'(He) has eaten everything.'

b. Oter tout ta.

empty all that

'(I) empty all that.'

According to Hyams $(1983,1986)$, all children start out speaking 'Italian' with respect to the null subject option. The formulation of the pro-drop parameter I adopted was inspired by Rizzi (1982), who argued that in some languages (e.g. Italian, Spanish) Agr is essentially a subject pronoun making the overt expression of the subject DP optional; in other languages (e.g. English, French) Agr is not pronominal and null subjects are therefore not licensed. The particular parameter I suggested, as distinct from Rizzi's, clustered the null subject property together with several other properties of (early) grammar, including the lack of lexical expletives (e.g. in weather and raising constructions) and modals as a distinct verbal category. The developmental prediction of such a system was that children would show all the characteristics of the [+pronominal] Agr setting at the same time. And those children for whom the target is not a pro-drop grammar, for example English and German-speaking children, would lose all these properties at roughly the same time at the point at which the parameter was reset to a [-pronominal] Agr. Two developmental stages are therefore predicted with respect to null subjects (and other properties), Italian, then English (or German).

This particular implementation of a developmental or "real time" parameter setting model turned out to be empirically flawed in a number of respects (which I return to below), but the logic seemed, and still seems to me to be correct. There are, in particular, three noteworthy features. First, the parameter setting model provides a narrowly constrained, and hence more explanatory model of acquisition than earlier standard theory, rule-based models. The "rules" of early grammar and the "errors" that children make are not random, nor do they arise from principles not 
otherwise motivated. Deviations from the target, though "target-inconsistent," to use Rizzi's (2005b) terminology, are still UG-consistent. Thus, as I noted in Hyams $(1983,1986)$, parameter theory gives a precise sense to the claim that child grammars are not fundamentally different from adult grammars (cf. also Klein 1982 and White 1981), a hypothesis that is now known as the continuity hypothesis, a term coined by Pinker (1984). Second, the deductive structure of the parameters, subsuming what would otherwise be disparate grammatical properties that would have to be individually learned, goes some distance towards accounting for the speed and ease of acquisition - the logical problem of language acquisition. Third, parameter (re-)setting provides a partial solution to what Felix (1987) called the 'stage-transition question', viz., what accounts for the transition from one stage (i.e., grammar) to the next?

Despite satisfying these desiderata of a generative theory of language development, there were problems with the pro-drop hypothesis, some of which were apparent almost immediately. First, the hypothesis is inconsistent with certain aspects of learnability theory, in particular, a developmental interpretation of the subset principle (Berwick 1982), according to which any parameter that is incorrectly set in development should generate a language that is a subset of the target. In the case of the pro-drop parameter, the [-pronominal] setting, i.e. English, which allows only overt subjects, is a subset of the [+pronominal] setting, Italian, which allows both null and overt subjects. It therefore seemed counterintuitive that Italian should be the initial setting (cf. also Lillo-Martin 1994). In Hyams $(1983,1986)$ I finessed this problem by showing that because of the expletive pronoun and modal properties subsumed by the parameter, the languages generated by the two values do not really fall into a subset relation. For example, though Italian is a superset of English with respect to referential subjects, as just shown, English allows lexical expletives (It's cold outside) and Italian does not, reversing the subset relations. Moreover, in English modals constitute a separate verbal category that undergoes inversion ( $\mathrm{Can} /$ have you dance?) and can be stranded under ellipsis, as in tags (You can't sing, can you?), etc., while Italian has neither of these properties. So in these respects as well, English is a superset of Italian. ${ }^{2}$ The combined effects are that English and Italian are not in a subset-superset relationship, but rather form intersecting sets. The subset principle is therefore vacuous. The only relevant requirement - that there be positive evidence to tell the English (and German, etc.)-speaking child that she is not in a pro-drop language - is satisfied by lexical expletives and the broader distribution of modals.

\footnotetext{
${ }^{2}$ A third trigger suggested in Hyams $(1983,1986)$ is the appearance of overt pronominal subjects in contexts that would be infelicitous in an adult NS language, for example, a 3rd person pronoun whose antecedent is well established in the discourse situation, as in (i):

(i) Mario ha mangiato troppo. Adesso (*lui) si sente male.

Mario ate too much. Now he feels sick.

As I will discuss below children have early knowledge of the pragmatic constraints on pronouns and null subject use.
} 
The hypothesis that modals and expletives constitute triggering data immediately brought to the fore a second problem. Surely, children hear lexical expletives, questions, and tags at a very early age. So why don't these data, if they are indeed triggers, have any effect until age 3 or so, the point at which children seem to stop dropping subjects? Parameter resetting sets limits on the range and direction of the transitions between stages, but it does not explain the timing. Borer and Wexler (1987) labeled this the "triggering problem", the solution to which, they argued, is to assume that principles (and perhaps parameters) of UG undergo maturation. On this view the pro-drop parameter becomes available for setting during the 3rd year, and so the triggers are irrelevant until that point.

Elaborating somewhat on the parameter maturation idea just mentioned, we might assume that parameters are not all available to be fixed at the initial state, but rather come "on-line" according to some sort of developmental schedule. A priori there is nothing implausible about this suggestion. However, Borer and Wexler (1992) were at pains to argue that maturation does not entail discontinuity in development, discontinuity in the specific sense of being unconstrained by UG. They thus proposed that maturation is "UG-constrained." For example, regarding A-chain maturation, the focus of their 1987 paper, during the pre-A-chain stage children's grammars generate a smaller set of representations than the adult grammar, but do not generate impermissible structures.

With respect to parameters, however, the situation is rather different. To say that the pro-drop parameter is off-line, hence unset, during the first 3 years of life means that the grammatical representation of subjects in the child's grammar is not UG-constrained as there is no specification of either the obligatoriness (as in English) or optionality (as in Italian) of overt subjects. We would therefore expect haphazard or random behavior in this domain. But this is not the case. As data from Valian (1990), Lorusso (2007) and Serratrice (2005) has shown, null subjects in child Italian have roughly the same frequency and distribution as in the adult grammar: Approximately $70 \%$ of subjects are null and they occur in both root and subordinate clauses. ${ }^{3}$ This target-like behavior suggests that Italianspeaking children have an early and correct setting of the pro-drop parameter, as argued by Valian. The same can be said for children acquiring other pro-drop languages such as European Portuguese (Valian and Eisenberg 1996). If the prodrop parameter emerges maturationally, then it should come on-line for the English-speaking child at the same time as the Italian- or Portuguese-speaking child, which is to say, well before age 3. Moreover, according to Borer and Wexler's proposal, it must be immediately set to English at that point. Otherwise, we run up against the triggering problem again. Thus, the triggering problem associated with the pro-drop hypothesis is not solved by maturation unless we assume Italian and English-speaking children mature at different rates, which seems implausible on its face.

\footnotetext{
${ }^{3}$ Valian (1991) puts the rate of null subjects in adult Italian at 50\% (following Bates 1976) while Lorusso (2007) and Serratrice (2005) place it close to the 70\% child null subject rate.
} 
I noted above that the pro-drop hypothesis avoids the subset problem because the parameter clusters together various properties that alter the standardly assumed subset-superset relations of this parameter. But this strategy only works to the extent that the developmental predictions of the model are empirically supported.

The corpora initially investigated seemed to support the co-occurrence of these different properties in real time, but later studies, in particular Valian (1991), showed that this clustering effect was not reliable. For example, Valian found in her crosssectional study that the English-speaking children produced modals and expletive subjects while still dropping referential subjects. ${ }^{4}$ Moreover, as noted above, in comparing Italian and English-speaking children matched for grammatical level, Valian found that they behaved differently with respect to null subjects and also overt pronouns; the English-speaking children showed far fewer null subjects (30\% vs. $70 \%$ for Italian children) and far more overt pronouns than would be expected if they were speaking a true pro-drop language. Similar differences were found between English-speaking and (European) Portuguese-speaking children (Valian and Eisenberg 1996), casting further doubt on the hypothesis that English null subjects were equivalent to those of a true pro-drop language. Finally, Valian (1991) (see also Roeper and Weissenborn 1990) also noted that in English null subjects did not occur in subordinate clauses, or in post-wh environments, in marked contrast to Italian child language (Guasti 1996). ${ }^{5}$ Similar root clause effects were found for French children (Crisma 1992; Levow 1995; Hamann 2000), for Dutch children (Haegeman 1995, 1996) and for German children (Clahsen et al. 1995). I return to these effects below.

\subsection{Morphological Uniformity}

Several other versions of the parameter missetting hypothesis followed. Jaeggli and Hyams (1988) proposed an analysis in terms of morphological uniformity. This account was based on the 'morphological uniformity principle' (Jaeggli and Safir 1989), according to which null subjects are licensed in languages with uniformly inflected or uniformly uninflected verbal paradigms. Jaeggli and Hyams suggested that while Italian children correctly assume a uniformly inflected (and hence null subject) language, English-speaking children incorrectly assume English is a uniformly uninflected (hence also null subject) language. Thus, children acquiring both types of language have null subjects as a grammatical option, but with different identification properties. Null subjects in Italian are identified by

\footnotetext{
${ }^{4}$ Wang et al. (1992) also found that the English-speaking children in their study used expletive subjects during the NS stage.

${ }^{5}$ Valian's observation of limited null subjects in post-wh environments is refined in Roeper and Rohrbacher (2000) who observe that $95 \%$ of post-wh null subjects occur in non-finite (bare verb) sentences (e.g. Where__ go/going?) while only 5\% occur in finite contexts (e.g. Where _ goes/ went/is going?). See also Bromberg and Wexler (1995) who replicate these results.
} 
person/number inflection on the verb, while null subjects in English are identified by a (possibly null) topic, as in discourse-oriented languages such as Chinese and Japanese (Huang 1984).

The morphological uniformity hypothesis still assumed a universal initial setting, viz., [+uniform], but this setting could be satisfied in two different ways depending on whether the input language was richly inflected (e.g. Italian) or not (e.g. English). In this sense it improved upon the original pro-drop idea because it allowed for some early influence of target language input. It also resolved a problem inherent in the pro-drop hypothesis, which is, how are early null subjects identified (or recovered) in languages like English, French and Danish which do not have "rich" agreement. The morphological uniformity hypothesis predicted that children exit the null subject stage once they "realize" that English does have some verbal inflection (in line with earlier proposals of Guilfoyle 1984 and Lebeaux 1987). This prediction was not confirmed. Most English-speaking children begin using present and past tense morphology before exiting the null subject stage (cf. Hyams and Jaeggli 1986; Sano and Hyams 1994; Valian et al. 1996; Ingham 1998). Similar results were observed for French (Rasetti et al. 2000) and Dutch (Hamann and Plunkett 1998), which, like English, were predicted to be uniformly uninflected during the null subject stage.

\subsection{The Topic Drop Hypothesis}

Other topic drop accounts of null subjects fared no better than the morphological uniformity hypothesis. The proposal that children start out with a discourse-oriented null subject grammar of the Chinese or Korean sort (Hyams 1991) cannot account for the differences in the frequency and distribution of missing subjects in English vs. Chinese-speaking children. In particular, English-speaking children show a huge subject-object asymmetry in the rate of argument drop while Chinese-speaking children drop both subjects and objects at roughly target-like rates from the earliest stage (Wang et al. 1992; cf. also Kim 1997 on argument drop in Korean child language.) Similar considerations hold for an analysis of early English as a topic drop grammar of the Germanic sort (Hyams and Wexler 1993), languages that typically license both subject and object drop provided the argument is fronted to Topic position.

\subsection{Competing Grammars Hypothesis}

The parameter setting models discussed above all involve the assumption of a default or initial parameter setting which may or may not be correct for the target language. In contrast to this, Valian (1991) proposed that multiple parameter settings (viz. grammars) may be initially available to the child (see also Fodor 1998 
and Roeper 2000 for similar suggestions). Thus with respect to the null subject phenomenon, she suggested that children initially entertain both the pro-drop and non-pro-drop options on an equal footing, wavering between the two grammars until sufficient evidence accrues to favor one over the other. Valian's rationale for this model is based on her assumptions about the child's parser. The child's parser, she observes, being parasitic on his grammar, cannot analyze input not generated by that grammar. Therefore, it cannot in principle analyze the triggers necessary to induce a parameter resetting. So, if the initial setting of the parameter is a pro-drop grammar, the English-speaking child would be unable to analyze the lexical expletives or first position modals, etc., which do not occur in true pro-drop languages, and, according to Hyams $(1983,1986)$ are necessary to reset to the correct non-prodrop grammar. Because the assumption is that the child cannot use as triggering data any input that is not generated by her current grammar, that is, any input that results in a failed parse, she must necessarily have access to both parameter values. Armed with both grammars/parsers, the child is able to parse all of the relevant input. Elsewhere (Hyams 1994) I have defended the pro-drop analysis against this particular criticism. On a parameter setting model grammatical development is generally conceived of as a 'failure-driven process' (Wexler and Culicover 1980; Clark and Roberts 1991). The child moves from one grammar or parameter value to another as she encounters input data that are unanalyzable (or unparsable) under her current grammar. Under the triggering assumption, the parsing paradox described by Valian does not block development. Rather it drives it, as it is precisely the assumption of a failed parse under some parameter value that triggers the resetting to the other value. ${ }^{6}$

More recently, Yang (2002) has proposed a formal version of the multiple grammars model, which also incorporates a statistical component. According to his 'variational' model, the learner has available multiple grammars to analyze the input. When a particular grammar succeeds in assigning an analysis it is rewarded (given more weight in the hypothesis space), it if fails it is punished. As learning proceeds, the more successful grammar becomes stronger, eventually pushing out the competitors. The speed with which the learner eliminates an incorrect grammar is a function of the frequency of the disconfirming evidence in the input for that grammar.

With respect to the null subject phenomenon, Yang proposes that the child's initial hypothesis space is defined by three grammar types: an Italian pro-drop grammar, a Chinese topic drop grammar, and an English non-null subject grammar. The high frequency of null objects in the Chinese input allows the Chinese-speaking

\footnotetext{
${ }^{6}$ There are a number of questions raised by this model. For example, how does the parser "know" which parameter is misset? A case in point, discussed at length in Gibson and Wexler (1994), is the German/Dutch child faced with a verb second sentence. This data could in principle trigger a (re) setting of the head-direction parameter to head first VO order (which would be incorrect according to many analyses of V2 languages), or it could trigger the verb second parameter to a (correct) positive value. For further discussion of this issue and related matters, see Clark and Roberts (1991) and also Gibson and Wexler (1994).
} 
child to quickly eliminate the English and Italian grammars, neither of which permits null objects. The Italian-speaking child can also quickly converge on the target, eliminating the English grammar on the basis of frequent null subjects in the Italian input, and the Chinese grammar on the basis of argument $w h$ questions with null subjects, as in (4a). ${ }^{7}$ Yang observes that Chinese does not permit null subjects with argument topics, only with adjunct topics (cf. $4 \mathrm{~b}, \mathrm{c}){ }^{8}$

(4) a. Chi $\mathrm{i}_{\mathrm{i}}$ ha bacciato $\mathrm{t}_{\mathrm{i}}$ ?

Who has (he) kissed?'

who _ has kissed

b. Zai gongyuan-li ${ }_{i}$ [da-le ren]

In park-loc beat-asp people

'It is in the park (but not at school) that (he) beat people up.'

c. $\quad$ Sue $_{\mathrm{i}}\left[\mathrm{xihuan}_{\mathrm{i}}\right]$

Sue likes

'It is Sue (but not Mary) that (he) likes.'

As for the English-speaking child, she eliminates the Italian grammar on morphological grounds; the English input does not contain unambiguous agreement (a necessary feature of the pro-drop option on Yang's assumption). Given that uninflected forms are very frequent in the English input, the Italian pro-drop grammar should disappear from the competition quickly. On the other hand, the Chinese option is harder to eliminate. This is because the only relevant disconfirming evidence, according to Yang, is expletive there sentences (not possible in topic drop grammars), which occur infrequently in the input (under $1 \%$ by Yang's estimation). ${ }^{9}$ The English- speaking child therefore maintains both an English non-null subject grammar and a Chinese topic drop grammar (until roughly age 3 the end of the NS stage)

The co-existing Chinese and English grammars explain several properties of the early English NS stage. First, we expect null subjects, but not at the frequency that they occur in a true topic drop language because English-speaking children access the Chinese grammar only probabilistically, unlike Chinese children who do so $100 \%$ of the time. ${ }^{10}$ Most interestingly, the variational model also predicts that

\footnotetext{
${ }^{7}$ Yang estimates that the frequency of sentences such as (5a) in the input to Italian children at about $15 \% \mathrm{He}$ does not provide any information about the basis for that estimate.

${ }^{8}$ Yang assumes, as is standard since Chomksy (1977), that wh fronting and topicalization are essentially the same process, both involving movement to Spec CP. Chinese does not have overt $w h$ movement.

${ }^{9}$ Yang does not say why he does not include expletive $i t$ as disconfirming evidence since it is also not possible in Chinese (Wang et al. 1992).

${ }^{10}$ According to Wang et al. (1992) 2-year old Chinese-speaking children drop subjects at a rate of about 55.7 while the English-speaking children in their study had a drop rate of about $26 \%$.
} 
English-speaking will drop objects and that the ratio of null subjects to null objects (NO) will be the same as for Chinese-speaking children (when the English data are scaled up to $100 \%$, as if they were monolingual Chinese-speaking children). This prediction is confirmed when tested against data in Wang et al. (1992). The null object (NO)/null subject (NS) ratio for the Chinese-speaking children is $36 \%$ $(56 \% \mathrm{NS} / 20 \% \mathrm{NO})$ and the ratio for the English-speaking children is $32 \%(26 \%$ $\mathrm{NS} / 8 \% \mathrm{NO}){ }^{11}$

Another prediction of the variational account of NSs is that English-speaking children will drop subjects in adjunct $w h$ questions, but not in object $w h$ questions, paralleling the argument/adjunct asymmetry in Chinese topicalization discussed in the text (cf. 5b,c). Yang reports that this asymmetry is confirmed in Adam's data (Brown 1973). ${ }^{12}$

Despite these very interesting results, the variational model also suffers from some serious empirical shortcomings, the most important of which is that NSs in non-null subject languages are heavily skewed towards non-finite contexts, especially root infinitives (Guilfoyle 1984; Kramer 1993; O’Grady et al. 1989; Poeppel and Wexler 1993; Sano and Hyams 1994; Phillips 1995 among others). With respect to English specifically this non-finiteness effect shows up in several grammatical contingencies. First, as Valian (1991) observes, null subjects do not occur with modals (which are inherently finite in English). Nor do they occur with finite forms of the copulas (is, am, are) of the copula (Sano and Hyams 1994). ${ }^{13}$ Additionally, as observed in Roeper and Rohrbacher (2000) and Bromberg and Wexler (1995), NSs in wh questions virtually never occur in questions with finite verbs (e.g. *Where _ goes/went?), but are restricted to bare verb contexts (e.g. Where _ go?) (see note 5). Finally, they do not occur in embedded contexts (Valian 1991; Roeper and Weissenborn 1990). Yang (2002) does not discuss these contingencies and it is difficult to see how the variational model can account for them, the restriction to root contexts in particular, given that Chinese NSs are not constrained in this way. In this respect it fares no better than previous parameter setting models, as I will discuss in the following section.

\footnotetext{
${ }^{11}$ The ratio of NS to NO in other English-speaking children is considerably lower. Valian's (1991) Group 1 children have a NS/NO ratio of $20 \%$ (36\% NS excluding $w h$ questions and $8 \%$ NO). The ratio of NS/NO for Adam, Eve and Sarah (based on Bloom 1991) is 16\% (55\% NS/8\% NO). It is possible that the discrepancies are due to different coders and coding procedures.

${ }^{12}$ It is difficult to evaluate this result, first because it is based on only one child. Also, studies that track children's early production of wh questions (e.g. Tyack and Ingram 1977) have shown that where questions are the most frequent early on. It is therefore possible that Adam uses disproportionately more where questions in the earlier files when he is also using more null subjects, but that these are independent factors.

${ }^{13}$ Hamann and Plunkett (1998) find a similar asymmetry in missing subjects in Danish-speaking children. Missing subjects are significantly more frequent with finite lexical verbs than with the finite copula.
} 


\subsection{Null Subjects and RIs: The PRO Hypothesis}

As just noted, another extremely important finding that directly challenges the parameter missetting accounts of early missing subjects is the finding that in the acquisition of many non-null subject languages there is a close association between missing subjects and absence of finiteness on the verb (Guilfoyle 1984; Kramer 1993; O'Grady et al. 1989; Poeppel and Wexler 1993; Sano and Hyams 1994; Phillips 1995). Sano and Hyams proposed that the null subject phenomenon is not due to a missetting of the null subject parameter, but rather to the fact that an underspecified Infl (responsible for non-finite root clauses) licenses a PRO in subject position. While Sano and Hyams focused on early English, Kramer (1993) reached similar conclusions based on data from German and Dutch. ${ }^{14}$ The PRO hypothesis explains why in Dutch, German and other non pro-drop languages, null subjects seem to occur disproportionately more often in non-finite root clauses (see Hoekstra and Hyams 1998 for summary of cross-linguistic findings). This is in marked contrast to the situation in Italian and other true pro-drop languages where the null subject pro, is licensed in finite contexts like a lexical pronoun. It is also unlike Germanic topic drop in which the dropped topic (subject or object) (arguably licensed by verb movement to $\mathrm{C}(\mathrm{V} 2)$ ) is also restricted to finite contexts.

The association between missing subjects and RIs thus constitutes further evidence against the parameter account - at least as regards null subjects in non-finite clauses. However, as observed in Hamann and Plunkett (1998) and Rasetti et al. (2000), there remains a significant number of null subjects in finite contexts - ranging from $10 \%$ to 55\% across different children and languages (see Rasetti et al. 2000 for summary of statistics; also Hoekstra and Hyams 1998). Of particular interest are the null subjects in finite clauses in English, French, and Danish, languages that do not have a pro-drop or topic drop option. Thus as Rizzi (2000, 2005a, b) observes, a parameter missetting account may still be valid for these cases. In what follows I restrict my discussion to null subjects in finite clauses and I will assume that the missing subjects in non-finite clauses are licensed by whatever mechanisms license PRO in infinitival contexts in adult grammars (the PRO theorem, null case, etc.). ${ }^{15}$

\subsection{Null Subjects in Finite Clauses}

Restricting our attention to finite clauses, as already noted, an accumulation of cross-linguistic data has shown that the distribution of null subjects in Italian child language is like adult Italian (Guasti 1996; Rizzi 2005a, b). Similarly, Chinese and

\footnotetext{
${ }^{14}$ To my knowledge, Weverink (1989) was the first to note the strong relationship between null subjects and RIs, based on Dutch child language. She proposed a more pragmatic type of analysis according to which RIs are topic-comment structures in which the topic is optional.

${ }^{15}$ It is also possible that the RI phenomenon itself results from a parameterized system, for example, Rizzi's (2005a, b) proposal that RIs result from VP truncation.
} 
Korean children drop both subjects and objects like adult speakers (Wang et al. 1992; Kim 1997) and Dutch/German-speaking children omit subjects and object in first, that is topic position, like their parents (de Haan and Tuijman 1988). It seems that the parameters responsible for null arguments - the pro-drop parameter and null argument parameters of both the Chinese and Germanic sort - take their place among other well-studied parameters such as V to I and V2, that appear to be correctly set from the earliest observable point (Pierce 1992; Poeppel and Wexler 1993). ${ }^{16}$ If children acquiring these various languages show early morphosyntactic convergence (EMC) (Hoekstra and Hyams 1998) (or 'very early parameter setting' (VEPS) - Wexler 1998), it stands to reason that English (and French and Danish)speaking children do too. ${ }^{17}$

So, let us assume in fact that English/French/Danish-speaking children also have correct, i.e. negative, settings of the pro-drop and topic drop parameters. Nonetheless, these children omit subjects at high rates (see Hoekstra and Hyams 1998 for summary of statistics). One possibility is that subject drop is due to performance factors, as first suggested in L. Bloom (1970) and more recently, in Bloom (1991), Valian (1990) and Gerken (1991) among others. I return to this proposal below. Alternatively, children may drop subjects under a parametric option that is different from the parameters discussed thus far, as has been suggested by Rizzi (2005a, b).

\subsection{Root Subject Drop and Truncation}

Rizzi (2005a, b) proposes that subject drop in early English (and French) is an instance of 'root subject drop' (RSD), a principle according to which a subject may be null in the specifier of the root. These null subjects at the edge of the root are accessible to discourse identification. His idea is that children initially assume a positive value of this parameter under pressure from a limited production system, in accordance with a formal strategy as in (5).

\footnotetext{
${ }^{16}$ Yang (2002) challenges the claim that the V2 parameter is set early based on the observation that many of children's early finite utterances are V1. However, it has long been established that V2 is the surface manifestation of verb movement to Comp (den Besten and Hans 1977; Koster 2003), and is associated with topicalization of some XP to Spec CP. Children (like adults) drop the XP in topic position (subject, object or adverb) yielding a verb initial sentence (Haegeman 1994). V2 (like all rules) is a structural, not linear notion. What is relevant to determining if the child has set the V2 parameter is whether there is V to $\mathrm{C}$ movement, which includes both V1 and V2 utterances. By this correct, structural criterion the evidence overwhelmingly supports the claim that children set the V2 parameter very early in development (Verrips and Weissenborn 1992; Wexler 1994; Poeppel and Wexler 1993; Hyams 1992).

${ }^{17}$ See Yang (2002) for an alternative view, according to which a parameter may be at different times in different languages depending on the frequency of disconfirming evidence in the input. See Sect. 2.4.
} 
(5) Adopt parametric values which reduce the computational load on the production system and are not contradicted by positive evidence" (Rizzi 2005b, (7)).

Rizzi suggests that the computational strategy in (5) is a temporary competitor to the subset principle, allowing an initial superset language, in this case a null subject language. The "unlearning" of this superset value happens maturationally. As the production system matures, the child, under pressure from the subset principle, abandons this strategy unless supported by positive evidence. Thus, children born into languages that have no pro-drop or topic drop options will nevertheless drop subjects in root contexts and only in root contexts.

RSD receives support from a number of adult languages. Rizzi reports on various languages, such as Levantine Arabic (Kenstowicz 1989), Corsican, and certain varieties of Brazilian Portuguese in which subject drop is limited to main clauses, in contrast to what occurs in "true" NS languages like Italian. A similar pattern is observed in Gruyère Franco Provençal (De Crousaz and Schlonsky 2003), in which subject omission is possible only from initial position, hence neither in $w h$ contexts or with preposed adjuncts. Rizzi also proposes that Germanic topic drop is an instance of RSD.

RSD is heavily dependent on an assumption of clausal truncation (Rizzi 1993/1994) and, by hypothesis, on the variation that languages show with respect to the level at which truncation is possible. Rizzi's original truncation hypothesis (Rizzi 1993/1994) held that young children (roughly to age 3) lack the grammatical axiom that the root clause $=\mathrm{CP}$ (or Force $\mathrm{P}$ in more recent proposals). Accordingly, they may have 'minimal projections' where the adult may not, terminating, for example, at the VP or IP (FinP) level. In more recent work, Rizzi (2005b) observes that adult languages also vary in the choice of categories that can be taken as the root. He proposes the structure of the left periphery as in (6) with Force as the universal default root category while other layers can be taken as root by specific languages.

(6) Force ... Top ... Foc ... Fin ... AgrS ... T ...

Thus, "pure" topic drop languages, such as German and Dutch, have the option of truncating at TopP, making the specifier of TopP a target of omission, while Levantine Arabic, Corsican, and certain varieties of Brazilian Portuguese allow truncation at the FinP level, and hence license omission in the specifier of FinP. Other possibilities exist as well. Truncation at the VP level gives rise to root infinitives (RIs) (Rizzi 1993/1994); truncation at FocP gives rise to systems allowing null wh operators, and truncation below ForceP would license null complementizers in declarative (as opposed to interrogative) clauses. (See Rizzi 2005b for further details.) UG makes available various truncation options, as exhibited by the range of adult languages just noted (and perhaps others yet to be discovered), and children set (and may misset) the "point of truncation" value for their language. Thus, RSD is not a parameter per se, but rather, the parametric options derive from the different truncation loci. 
The RSD model accounts for a number of important properties of early subject drop. Central among these are the root/first position effects discussed earlier (Valian 1991; Roeper and Weissenborn 1990). It also dissociates subject drop in English/French/Danish from null subjects in Italian and other true pro-drop languages, a desirable result given the empirical difficulties faced by the pro-drop hypothesis, and it allows for the omission of both referential subjects and expletives (not possible on a topic drop analysis because Top does not house expletives). Additionally, it explains the similar trajectories of RIs and null subjects in finite contexts in Danish. French and Dutch (Hamann and Plunkett 1998; Rasetti et al. 2000; Haegeman 1995) if both RIs and NSs result from truncation, of VP and IP, respectively (see note 15). Finally, it provides an answer to the important question of why some parameters (e.g. head direction, V to I, V2) are fixed early in development (according to VEPS or EMC) while others (e.g. root null subjects, RIs) are delayed much longer: The solution to this puzzle is that parameters with the potential to ease the computational load on the production system by licensing null elements (e.g. null arguments, null tense/Aux as in RIs), and which are not contradicted by positive evidence, are likely to be set later in development. ${ }^{18}$ In all these respects, then, the root subject drop as an account of NSs in finite clauses specifically, is superior to previous parameter setting models of early null subjects.

The RSD hypothesis does raise a few questions, however. The first concerns the trajectory of subject omission in non-pro drop languages and the second, the interaction of RSD with other argument omission parameters in languages such as Italian or Dutch. Finally, there is the question to what extent the empirical evidence really supports the claim that null subjects are (in part) a performance effect. I will now discuss the first two of these points, and return to the performance question below.

We noted earlier that the pro-drop and topic drop parameters are fixed early in development (either positively in the case of Italian, and German/Dutch children respectively, or negatively as by English/French/Danish-speaking children). But adult English (and other non-pro drop languages such as French) also have a restricted subject drop option, so-called 'diary drop', discussed in Thrasher (1977) and Haegeman $(1990,1992)$ and illustrated in (7). Diary drop adheres to certain well-defined structural conditions. Subjects may drop, but objects may not. More generally, subjects may be omitted only from first position, as in (7a, b), so not following $w h$ phrases or preposed adjuncts, as in $(7 \mathrm{~b}, \mathrm{c}$ ) (from Haegeman 1990, 2000).

\footnotetext{
${ }^{18}$ Although the pro-drop parameter also licenses null subjects, it is set early in development because there is positive evidence in the form of rich inflection, i.e. a highly differentiated agreement system in languages like Italian (Rizzi 2005a, b; Yang 2002). We return to the question of whether and how pro-drop and RSD might interact below.
} 
(7) a. Wonder what they're doing.

b. Could do better. (from school report)

c. *When will come back?

d. *That book, don't like.

e. M'accompagne au Mercure, puis a la gare.

'(he) takes me to Mercure, then to the station...'

(Paul Léautaud, Le Fleau, Journal Particulier, 1917-1930, pp. 69-70)

The observation that English/French-speaking children's null subjects are restricted to root clauses, and more specifically, to first position (Valian 1991; Roeper and Weissenborn 1990) is quite consistent with diary drop. So it seems logical to assume that the mechanisms that allow for diary drop in adult English also operate on children's grammars. But if so, then children's initial option to truncate at FinP (making RSD possible) is a correct target setting and English/ French-speaking children show early morphosyntactic convergence with respect to this parameter (as with many other parameters). Indeed, Rizzi (2005a, b) takes diary drop to be an instance of RSD. On his analysis (see also Haegeman 1994) diary drop results from truncation at the FinP level (see 6) - an option realized by English and French-speaking adults. So, assuming children are showing early convergence on the adult target, what then accounts for the higher frequency and broader application of RSD by children, who clearly are not restricting subject drop to contexts that are acceptable in the adult language? And how do children gradually reduce the frequency and distribution of RSD to adult norms under the reasonable assumption of no negative evidence? I return to this question in Sect. 6. Additionally, if RSD is diary drop, it is not obvious how to account for the virtual absence of NSs with modals (1991) and finite forms of the copula (Sano and Hyams 1994) in early English, as these are possible under adult diary drop (e.g. 7b).

On the other hand, it is possible that children give up RSD as their production capacities mature, in accordance with the subset principle. On this view, the RSD option would then have be reactivated at some later point to account for adult diary drop. That is, children would learn on the basis of positive evidence that subjects can be omitted in specific registers, but not otherwise. Assuming this is the case, we would expect a trajectory of missing subjects of the following sort: an initial period of frequent missing subjects, followed by a period of no subject drop at all, and then a later introduction of subject drop in diary and contexts. Conversely, if children's early RSD is effectively diary drop and they never reset the relevant parameter, we might expect a gradual decrease in null subjects ending with a frequency and distribution that matches the adult's. In one case we would see a strong discontinuity and in the other case we would not.

I know of no detailed longitudinal study of subject drop in English that would answer this question at this time. Rasetti et al. (2000) traces the frequency of null subjects in several French-speaking children over several months. There we see a gradual decline in subject drop in finite contexts ending at a frequency of between 
$10 \%$ and $30 \%$ depending on the child. However, the periods of observations are quite early (ending at 1:11 to 2;9 depending on the child) and therefore, it is impossible to know whether these children would subsequently stop dropping subjects completely and only later begin adult-like diary drop. ${ }^{19}$

A second question concerns the interaction of RSD with other argument omission options, in particular the pro-drop and topic drop parameters. The English case seems clear. Children have negative settings on the pro-drop and topic drop parameters, and a positive setting for RSD, that is, FinP truncation. But what of, say, Italian children, who correctly set the pro-drop parameter to a positive setting on the basis of rich verbal agreement in their input language, as proposed in Yang (2002) and Rizzi (2005a, b). If RSD is an initial "unmarked" option, is it also the case for children acquiring pro-drop languages? Presumably so, unless there is some blocking mechanism according to which RSD is turned off as pro-drop is activated. Perhaps the pro-drop option is a valve that reduces performance pressures on the child and thus allows an earlier abandonment of the RSD option. On the empirical front, if children assume both pro drop and RSD, we might expect a higher frequency of null subjects earlier on, dropping to adult rates at the RSD option disappears. There are conflicting data on this point. Valian (1991), following Bates (1976), reports that Italian adults drop subjects at a rate of approximately 50\%, while Italian children drop at 70\%. Similarly, Valian and Eisenberg (1996) report that Portuguese-speaking children drop subjects at higher rates than adults. These results would support the hypothesis that both RSD and pro drop operate initially. However, other studies show a similar null subject rate in Italian children and adults (Serratrice 2005; Lorusso et al. 2004) and in Spanish-speaking (Bel 2003) and Catalan-speaking children (Cabré Sans and Gavarró 2006) suggesting continuity of pro-drop and a blocking of RSD.

Similar questions arise in connection with topic drop languages if we assume that object topic drop (or V2) is the trigger for topic drop or TopP truncation, on Rizzi's model Dutch and German-speaking children have evidence for a positive value along the relevant parameter (while English/French/Danish-speaking children do not have such evidence). ${ }^{20}$ But if RSD is also an initial option - and one that is not blocked by topic drop - then we would expect subject topic drop to occur at higher rates in children than in adult speakers (the effect of both IP and TopP truncation), while object drop should remain constant (only TopP truncation). I know of no relevant longitudinal data, but this would be an interesting issue to pursue. If there is an asymmetry between subject and object drop along the lines just mentioned, it may be that topic drop blocks diary drop because they both instantiate the $\mathrm{RSD} /$ truncation parameter, while pro drop is a separate parameter that acts independently.

\footnotetext{
${ }^{19}$ Hamann and Plunkett (1998) provide month by month frequencies of null subjects in two Danishspeaking children, but it is difficult to determine from their graphs whether there is a steady decline or a more discontinuous type of development. We leave this issue open for now.

${ }^{20}$ Hamann and Plunkett (1998) show that Danish, though it is a V2/topicalization language, does not readily allow topic drop. Under $1 \%$ of adult utterances have dropped topics.
} 
In short, although a great deal is known about the overall frequency and distribution of null subjects in various child languages, it would be useful to have a more detailed accounting of the trajectory of null subjects (and objects) over time. This would provide a clearer picture of the interaction among different parameters, and also between the grammar and whatever effects might arise from an immature production system, or as will be discussed in more detail below (Sect. 5), in interaction with the pragmatic/discourse system.

\section{Grammar-External Accounts}

The RSD hypothesis is motivated in part by considerations of grammar-external production constraints; the formal mechanisms of subject drop fall squarely within the grammar, but children adopt RSD under pressure from a constrained production system.

Other proposals claim that subject omission is purely an effect of production limitations, and is not grammatically licensed (Bloom 1970, 1991; Valian 1990, 1991). Still other proposals hold that missing subjects depend on aspects of information structure, viz. that omission is permitted under certain situational and discourse conditions. In this section I will review the empirical basis for the claim that null subjects result from an overworked production system. Later, in Sect. 5, I will return to the effects of discourse conditions on subject omission.

\subsection{Processing Limitations}

Pure processing accounts of the null subject phenomenon in child language (e.g. Bloom 1991; Valian 1991) make several important claims. The first is that null subjects are not a grammatical option for young English-speaking children and so do not appear in the grammatical representation of the sentence. Instead, subjects are grammatically represented as either full lexical NPs such as John, the boys, or as pronouns, and are subsequently dropped during the production of the sentence because of a constraint on output. This claim prompted Hyams and Wexler (1993) to refer to this model as the output omission model (OOM). A second claim, made specifically in Bloom (1991), is that lexical subjects such as John impose a greater processing load than pronouns, and that omitting the subject completely imposes the lightest load. Thus, the probability of omission is a function of the "heaviness" of the subject, with lexical subjects more likely to be omitted than pronoun subjects. A third claim is that processing load is greatest at the beginning of a sentence. According to Bloom (1991), "the processing load at every point is proportional to the number of yet-to-be expanded nodes that must be kept in working memory" (Bloom, p. 501), so that elements at the onset of an utterance are more likely to be 
dropped than elements at the end. This last claim is intended to account for the most salient fact about subject drop, which is that it occurs at a far higher frequency than object drop, in early English.

Prima facie, the grammatical contingencies between missing subjects and other parts of the sentence structure seem to argue strongly against a pure processing account. For example, the NS-finiteness relationship discussed earlier is unexpected if the "heaviness" of the subject affects the structural complexity of the VP: a finite VP (including finite verb/copula or modal) presumably recruits more processing resources than the infinitive and so should occur more frequently with null subjects than do RIs, contrary to fact. In addition, subjects in English can drop in post-wh contexts (with non-finite verbs, see note 5). This is also unexpected. In these cases, it is the first position wh phrase that should drop rather than the subject. And as with the RI-null subject contingency, the fact that the subject drops in $w h$ questions with non-finite (bare) verb is unexpected as these are presumably less complex than finite verbs.

Other findings seem to support the OOM. Bloom (1991) observed that in the spontaneous corpora of Adam, Eve, and Sarah that VP length (measured in terms of words) decreases as a function of the heaviness of the subject: VPs are shortest in sentences with lexical subjects, longer with pronouns, and longest when the subject is omitted. ${ }^{21}$ The intuitive explanation for this effect is that the more resources the child takes up in producing the subject, the less are available for expanding in the VP. The VP length effect is replicated by Valian in both spontaneous speech (Valian 1991) and elicited imitation (Valian et al. 1996) in English-speaking children and in Hamann and Plunkett's (1998) study of the spontaneous productions of two Danishspeaking children.

Interestingly, while finding that VP length decreases as a function of subject "heaviness", Hamann and Plunkett also find that overall the MLU of subjectless sentences is shorter than in sentences with subjects, meaning that on average, processing resources, as measured by utterance length, do not determine subject omission. How can we reconcile these apparently conflicting results?

Hyams and Wexler (1993) ran the same VP length analysis on the spontaneous speech of several Italian adults, that is, adult speakers of a null subject language. Strikingly, we found the same VP length effect as a function of subject heaviness as was found for the children, although the overall MLUs for adults are obviously longer. The similarity between Italian adults and the English/Danish-speaking children strongly suggests that the VP length effect has little to do with production constraints (as presumably Italian adults are not so constrained), but rather, is associated with some - possibly pragmatic - factor associated with argument omission. I will elaborate on this idea in Sect. 5.

The claim that full NP subjects are more likely to be dropped than pronouns is also directly contradicted by experimental evidence. Both Gerken (1991) and

\footnotetext{
${ }^{21} \mathrm{~A}$ similar result was found many years earlier in Bloom (1970) who looked at the expression of subjects as a function of VP length in sentence with the verb make.
} 
Valian et al. (1996) have found that in elicited imitation young English-speaking children are less likely to repeat pronominal subjects than lexical NP subjects. In other words, pronouns are more likely to drop than full NPs. ${ }^{22}$ Valian et al. (1996) also found that children were less likely (though not significantly so) to repeat an expletive pronominal subject (e.g. it, there) than a referential one (e.g. I, we) and also that children were more likely to omit a pronominal subject when it followed a topic-introducing sentence, (e.g. See the three frogs. They catch flies) than when it did not have such an introduction. Both of these findings are unexpected on a production limitation model because the length of the experimental sentences is held constant across these conditions.

A second major statistical fact offered in support of the OOM is the finding that Italian children omit subjects at a rate of $70 \%$ whereas English-speaking children omit subjects at a rate of roughly 30\% (Valian 1991). Valian explains this difference under the hypothesis that English-speaking children are dropping subjects for performance reasons, whereas Italian children are taking advantage of a grammatical pro-drop option. But this argument based on frequency differences is a spurious one; there is no theoretical reason why a performance constraint should yield fewer null subjects than a grammatical option or vice versa. The frequency differences suggest that there is some difference between Italian- and English-speaking children with respect to the use of null subjects, but it does not speak to the question of where the difference lies. For example, it is equally consistent with the idea that RSD (for whatever reason) is less frequent than pro-drop.

Hyams and Wexler (1993) developed a formal model incorporating two of the central claims of the OOM; first, that null subjects are not a grammatical option for the child, but result from the dropping of a lexical NP or pronoun in production, and second, that lexical NPs are heavier, hence more likely to drop than pronominal subjects (Bloom 1991). This model predicts that missing subjects are more likely to result from the dropping of a lexical subject than from the dropping of a pronoun. Therefore, as children grow out of the performance limitation and subject omission ceases, the proportion of lexical subjects should increase. We found that this prediction was in no way confirmed. For both Adam and Eve there is a steady increase in the proportion of pronouns over time whereas the proportion of lexical subjects remains roughly constant. As Hyams and Wexler note, this "trade-off" between null subjects and pronominal subjects with the proportion of lexical subjects remaining constant is exactly what would be predicted if subject omission has a grammatical basis. In adult NS languages null subjects serve the same pragmatic function as pronouns in a non-null subject language (i.e. to refer to contextually specified information). The hypothesis that children's missing subjects are a grammatical option predicts that as English-speaking children abandon this grammar

\footnotetext{
${ }^{22}$ In Valian's study, this result held only for the lower MLU group. Children with an MLU $<3$ produced repeated $76 \%$ of pronouns and $90 \%$ of lexical subjects $90 \%$. The older group with MLU $>3$ repeated pronominal and lexical subjects equally often ( $92 \%$ vs. $95 \%)$.
} 
(whatever its precise characterization), there will be a marked increase in the proportion of pronominal subjects. ${ }^{23}$

The trade-off between null subjects and pronouns is also confirmed in Valian's (1996) imitation study, as well as in Hughes and Allen's (2008) study of the pragmatic/discourse conditions on missing subjects. (I discuss these conditions further in Sect. 5.) These results are not predicted by the processing account of subject omission.

\subsection{Metrical Effects}

The production limitations account of missing subjects argues that processing difficulties increase as a function of the sentence length. Gerken (1991) proposes, instead, that children's productions are constrained by a metrical template favoring trochaic feet, that is, a phonological unit consisting of a strong syllable followed by a weak one (S-W). Children apply this template to their output and drop weak syllables that do not align with the trochaic template. This template applies to words, favoring omission of the weak syllable in words like gi-raffe, which reduces to the strong syllable raff whereas a word such as ze-bra, which has an S-W structure, is less likely to reduce (Gerken 1994).

More relevant to the current discussion is the fact that the metrical template also applies at the sentence level, favoring omission of pronominal subjects in sentences such as (8).

(8) He loves her

W S W

In (8) he is a weak syllable that does not fit the trochaic template. On the other hand, the pronominal object her does not drop because it forms a trochaic unit with the verb. In this way the metrical hypothesis is able to account for the subject-object asymmetry in English. It is also consistent with the formal results in Hyams and Wexler just discussed (1993) that show that pronominal subjects are more likely to drop than full NP subjects; on the metrical analysis this is because pronouns are prosodically weak.

\footnotetext{
${ }^{23}$ It is also not possible to explain the trade-off between null and pronominal subjects by some independent factor having to do with the general difficulty of pronouns (relative to NPs) that makes them less likely to be used at the earlier ages. If this were the case, we would expect to see the same trends in object position that we see in subject position; that is, we should see an increase in pronominal objects over time. Hyams and Wexler (1993) showed that this is not the case. The proportion of pronominal to lexical objects remains roughly constant over time. This finding also casts doubt on Yang's (2002) hypothesis that null objects in early English result from a Chineselike topic drop grammar. If this were the case, we should also see a rise in object pronouns over time as null objects decrease.
} 
However, like the production limitations model, the metrical analysis does not explain the syntactic contingencies, for example, why subjects are more likely to be omitted in RIs than in finite clauses in many languages. Also, as noted by Hamann and Plunkett (1998), the metrical account does not generalize easily to other languages. For example, in German post-verbal subjects are omitted to a much higher degree than in situ objects though the metrical structure is the same (Hamann 1996), and in French object clitics are dropped from both iambic and trochaic feet (Hamann et al. 1996; Jakubowicz et al. 1996). Finally, as Valian (1996) observes, the metrical account also fails to account for her imitation findings that expletive subjects are omitted more than referential subjects, and also that pronominal subjects following topic sentences are dropped more often. In both these cases metrical factors are held constant. I discuss Valian's imitation study further in the next section.

\subsection{Spontaneous Production and Imitation}

Valian (1996) argues in support of a processing account of early missing subjects on the basis of an elicited imitation study with 19 children (ages 1;10 to 2;8). Her argument centers on a comparison of English-speaking children in two MLU groups, one with MLUs greater than 3 (MLU $>3$ ), the other less than 3 (MLU $<3$ ). According to Valian, the higher MLU group is adult-like with respect to the null subject option. In other words, the children in this group know that sentences require overt subjects. They imitate subjects at an overall rate of $87 \%$. The children in the lower MLU group, on the other hand, still drop subjects to a significant degree. They imitate subjects at an overall rate of $63 \%$.

Despite the difference in the overall rate of subject omission, the two MLU groups behave similarly with respect to factors that have been argued to indicate a pro-drop or Chinese-like topic-oriented NS grammar. Higher omission of expletive over referential subjects is indicative of a pro-drop grammar, and omission of subjects following topics, indicative of a Chinese-type topic drop grammar. As noted above, both the lower and higher MLU groups show more omission of expletive subjects over referential pronoun subjects (consistent with the pro-drop account), and both groups drop pronominal subjects more after a sentence introducing a topic (consistent with a Chinese-type topic drop account). On the other hand, the two groups differed with respect to the VP length effect: the lower MLU group showed shorter VPs as a function of subject type $(\mathrm{NP}<$ pronoun $<$ null subject, as in Bloom 1991), while the higher MLU group showed no such effect. Because the two groups differed in their overall rate of missing subjects, but showed similar effects with expletive vs. referential subjects as well as topic establishment, Valian concludes that they do not have different grammars. Therefore, she argues, subject omission in the lower MLU group is not a grammatical effect, but rather due to limited processing resources, as shown by the 
difference in VP length results. ${ }^{24}$ Valian also found that missing subjects do not correlate with a systematic lack of inflection, as would be predicted, for example, by the morphological uniformity hypothesis, or other accounts that tie subject drop to an underspecified or missing Infl. ${ }^{25}$

Valian's results are quite interesting. They argue against a pro-drop account of the sort proposed in Hyams $(1983,1986)$, and also against the idea that children start out with a Chinese-type topic drop grammar (Hyams 1991; Yang 2002). But they do not bear on Rizzi's RSD hypothesis which does not predict more expletive drop than referential pronoun drop (early English is explicitly not Italian on this analysis). Nor does it predict more subject drop following topic establishment (early English is also not Chinese according to RSD). Moreover, on the RSD hypothesis null subjects are licensed in finite contexts (Spec of FinP). So, the RSD hypothesis is not challenged by Valian's morphological results.

But what of the VP length results? Following Bloom (1991), Valian takes this result (which she found for MLU $<3$ group, but not for the MLU $>3$ group) as support for a processing account of missing subjects. However, the VP length effect is not problematic for the RSD account. Indeed, Rizzi's model specifically appeals to processing limitations as the reason children initially choose the "more economical" [+RSD] parametric value. I will return to the VP length results in Sect. 5 where I offer an alternative, pragmatic explanation for this effect, as originally suggested in Hyams and Wexler (1993).

\section{Converging Methodologies}

It is important to bear in mind that Valian's results are based on children's imitative language, in contrast to most of the earlier studies of missing subjects which are based on spontaneous production. That children's elicited imitation should resemble their spontaneous language is not surprising. As early as 1964, ErvinTripp and also Brown and Fraser showed that the imitations of "telegraphic" children mirrored their spontaneous productions; children drop subjects, auxiliaries, determiners, and so on in both cases. The usual assumption for why this happens has been that there is an underlying mechanism common to all linguistic performance, namely, the grammar. On this view, the child's imitations are

\footnotetext{
${ }^{24}$ Valian's explanation for the expletive and topic effects is that they are input driven, viz. that expletives can be more easily dropped in adult language. Even if this is true - as an instance of diary drop - it only pushes the interesting question back a generation. Why can adults drop expletives more easily? It is possible that for both children and adults expletives carry less informational content and hence, are more easily omitted according to pragmatic principles.

${ }^{25}$ I have in mind analyses such as Radford's (1990) very influential small clause hypothesis and the Clahsen et al.'s (1994) proposal that children lack Agr projections. There has been a great deal of discussion about the empirical problems associated with such accounts (particularly in languages other than English), which, for reasons of space, I will not review here.
} 
filtered through his grammar and the same grammatical rules (parameter settings, etc.) are therefore in play (Ervin-Tripp 1964; Brown and Fraser 1964; Lust et al. 1986, 1987).

The notion that imitation reflects competence has also been the rationale for the frequent use of imitation tasks to tap grammatical knowledge in areas as diverse as relative clauses, backwards and forwards anaphor, coordination, and head direction (see Lust et al. 1987 for review). As Lust et al. point out, the crucial point of these imitation studies is that they are designed to test a precise grammatical factor and other, performance-related factors, such as sentence length and complexity, are controlled for. Thus, if children respond differently with respect to the various conditions, this is a reflection of their grammatical competence. For example, Lust et al. (1986) showed that children are better at imitating postposed adverbial clauses which coincide with the right-branching structure of English(e.g. John rode the bike when he was at school), than preposed ones (e.g. When he was at school, John rode the bike) even though length is held constant. In fact, in a number of imitation studies the results go in the opposite direction of what is predicted by a performance account. For example, children are more successful at imitating sentence coordination (e.g. Push the truck and push the car) than reduced or phrasal coordination (e.g. Push the truck and the car), even though the former is longer than the latter. Similarly, English-speaking children do better when the reduction site is in a forward position (e.g. Push the truck and _ the car) than in a backwards position (e.g. Push and pull the trunk), where again, the length factor would predict the opposite result. Children acquiring languages with a left-branching structure show the opposite results.

Though it seems likely that different cognitive resources are recruited in spontaneous production and elicited imitation, it is possible that they are subject to some similar production constraint (as suggested by Brown and Fraser 1964). ${ }^{26}$ After all, both behaviors involve the production of an utterance. But suppose we eliminate the production component entirely. We might then expect different results if, indeed, production limitations are responsible for missing subjects. On the other hand, if we also find that children accept null subjects in comprehension, we can attribute this to the underlying grammar. ${ }^{27}$ In the next section I report the results of a comprehension study on null subjects.

\footnotetext{
${ }^{26}$ Brown and Fraser (1964) state "a basic factor causing the child's reduction of adult sentences is surely an upper limit on some kind of immediate memory span for the situation in which the child is imitating and a similar limit of programming span for the situation in which the child is constructing sentences" (p. 76).

${ }^{27}$ Valian $(1991,1996)$ in her discussion of VP length effects in imitation says that the results show the length of sentences that "children are hearing can also have an effect on their use of subjects" and that "the processing limitations begin their influence during the comprehension phase of the task and continue through production" (p. 162). It is not obvious that the effect found in imitation is due to a comprehension problem, as Valian implies, given that similar effects are found in spontaneous speech which has no obvious comprehension component.
} 


\subsection{Null Subjects in Comprehension}

Orfitelli (2008) conducted comprehension experiments to see if English-speaking children (who are productively in the missing subject stage) also understand and accept null subject sentences in comprehension (cf. also Orfitelli and Hyams 2007). Our hypothesis is straightforward: when children show the same (non-)adult behavior in comprehension and production (and imitation), this is due to the effects of the grammar - common to all linguistic performance. On the other hand, if the effect is strictly due to constraints on production (due to sentence length or metrical structure), then it should not show up in comprehension.

The experimental task is based on the truth value judgment (TVJ) methodology of Crain and McKee (1985). The design of the experiment exploits the fact that in English, null subjects are licensed in imperative, but not typically in declarative contexts (diary drop contexts excepted, as noted above). The children in the study see a scenario and then hear a comment made by an observing puppet, Mr. Bear. They are asked to be Mr. Bear's teacher for the day, and to tell him if his statements matched the scenario or not, and why. Thirty children (13 boys, 17 girls) were tested, ten children in each 6-month interval between $2 \frac{1}{2}$ and 4 years $(2.54$ 3.97 years, mean age 3.25 ).

There were four different scenarios in the task, each consisting of a story and an accompanying pair of pictures. The first of the pair was always a picture of two "big kids" named Mary and Billy, while the second picture was always of two "little kids" named Emma and Ben. In the "big kid" scenarios, the children are engaged in a particular activity, such as drawing a picture or playing with blocks, while in the "little kid" scenarios the children are shown next to the props (i.e. paper and crayons or blocks) but not using or playing with them. Each subject was told that the "big kids" are old enough to engage in these activities without being given permission, and, moreover, they do these activities every day. On the other hand, the "little kids" have to wait for their babysitter - Mr. Bear - to tell them that it's okay to play with the blocks, crayons, etc.

Before the experiment began, subjects were told that Mr. Bear's comments would either describe what the children were doing, or would tell them to do something. It was then established that it would be silly for Mr. Bear to tell the older children to do an activity they were already doing. It would, however, be appropriate for him to describe their actions. Conversely, it would be silly for Mr. Bear to describe the younger children performing an action they were not doing, but it would be appropriate for him to tell them to do the activity, because they were waiting for his permission. So the "big kid" scenarios provide the declarative context while the "little kid" scenarios provide the imperative context. Table 1 gives examples of the test sentences with adult judgments.

The declarative (a) and imperative (b) conditions serve as controls. High performance on these conditions indicates that the child comprehends declarative and imperative clauses in an adult manner, and understands the scenario and the task. Children who performed badly (less than seven out of eight items correct) on either 
Table 1 Example items with adult judgments ${ }^{\mathrm{a}}$

\begin{tabular}{|c|c|c|c|}
\hline & & $\begin{array}{l}\text { "Big kid"/declarative } \\
\text { scenario }\end{array}$ & $\begin{array}{l}\text { "Little kid"/imperative } \\
\text { scenario }\end{array}$ \\
\hline a. & They always play with blocks & Match & No match \\
\hline b. & Please play with blocks & No match & Match \\
\hline c. & Play with blocks & No match & Match \\
\hline
\end{tabular}

aPlaying with blocks was one of four scenarios. The other scenarios involved eating a cookie, drawing a picture, and putting on socks

Table 2 Individual performance on the null subject condition

\begin{tabular}{llll}
\hline & $2 ; 6-2 ; 11$ & $3 ; 0-3 ; 5$ & $3 ; 6-3 ; 11$ \\
\hline AC $(7-8$ correct $)$ & 1 & 2 & 7 \\
C $(2-6$ correct $)$ & 0 & 0 & 1 \\
BC $(0-1$ correct $)$ & 9 & 8 & 2 \\
\hline
\end{tabular}

the declarative or imperative condition were not included in any subsequent analyses. The sentence in (c) is the experimental null subject condition. The subjects were tested on whether they accept this sentence in declarative and imperative contexts. If children are adult-like they will give the responses in Table 1, they will accept the sentence (=match) for the "little kid" scenario, allowing an imperative meaning, and they will reject (= no match) for the "big kid" scenario, disallowing a declarative meaning. On the other hand, if children have a null subject grammar, they will accept the null subject sentence in the 'big kid' scenario, where the interpretation is declarative and also presumably allow it in the "little kid" scenario, assuming they also allow an imperative reading for NS sentences.

In addition, a 10-min audio recording was made of all children who participated in the judgment task. These transcripts provided information on the child's spontaneous production of null subject sentences. Children who showed a proportion of null subjects (in non-imperative contexts) greater than $30 \%$ were considered to be in the NS stage. This proportion of null subject utterances is roughly what has been observed in the natural production of English-speaking children in the NS stage (Valian 1991). If the NS stage is the result of a non-adult grammar, viz. one that that license null subjects, then we should see a high correspondence between an individual child's production of NS sentences and that same child's assignment of a declarative reading to the sentences in the null subject experimental condition.

The results were as follows: 30 of the 35 children tested performed well on declarative and imperative controls, and were thus included in the analysis of the null subject sentences. Children's individual performance on the null subject condition is shown in Table 2. Most of the children in the two youngest groups performed below chance (BC). Below chance means they got 0 or 1 item correct out of 8 in the null subject condition. By contrast, 7 out of 10 children in the oldest group performed above chance (AC), as compared to only two children in the younger age groups. Interestingly, only one child performed at chance $(C)$. The consistent $\mathrm{BC}$ performance of the younger groups indicates that they have a 
consistent analysis of the null subject sentences. All but two of the children in the youngest age groups accepted null subject sentences in declarative contexts, as is expected if they have a NS grammar. Ten of the children, 7 of whom were in the oldest group, showed adult-like performance. In contrast to the younger groups, the oldest children tested performed well above chance as a group. This increase in adult-like comprehension at $3 \frac{1}{2}$ years mirrors the decrease in production of NS sentences that occurs at this age.

This behavior in comprehension is predicted by grammatical accounts, but not by processing accounts, which hold that children's do not grammatically represent NSs, but rather drop phonological subjects in production because of limitations in the planning and/or executing of the sentence.

In addition, an individual subject analysis that compared each child's performance on the null subject condition of the judgment task to the proportion of NS sentences she produced in the recording showed a $100 \%$ correspondence. Children who were classified as being in the NS stage by the recording task were also classified as being in the NS by the comprehension task. This perfect correspondence again supports the grammatical account according to which children have a NS grammar that underlies both production and comprehension.

There was one unexpected result in Experiment 1. In NS languages, null subjects are licensed in both declarative and imperative contexts, and thus it is expected that children in the NS stage would accept the experimental NS sentences in both the declarative and imperative scenarios. This was not the case. While the younger children overwhelmingly allowed NS sentences in a declarative context, they unanimously rejected them in the imperative situations. A possible explanation for this result is that the NS children, for whom a subjectless sentence is ambiguous between an imperative and declarative structure, are being pushed toward the declarative reading because all of the control imperative sentences began with 'please'. If the children adopt a strategy according to which imperative usage requires 'please', this would induce them to interpret subjectless sentences lacking 'please' as declarative. To test this hypothesis, we did a follow up study. In the second experiment, we included vocative imperatives (e.g. Hey kids, play with blocks) to neutralize a potential 'please' strategy. We found the same overall pattern of results, i.e. one adult-like group that allowed only an imperative reading of NS sentences, and a second group that allowed declarative meaning (the NS group). In Experiment 2, however, the NS group allow *both* the imperative and declarative readings in equal measure. This supports the hypothesis that in Experiment 1 the children were using a 'please' strategy to disambiguate the otherwise ambiguous NS sentences (see Orfitelli and Hyams for further discussion). More generally, the results of the comprehension study strongly favor a grammatical account according to which missing subjects are a grammatical option in early language (to roughly age $31 / 2$ ), and not simply the output of an overwrought production system.

To sum up the discussion thus far, while children are certainly more limited than adults in their productive abilities, the statistical and empirical evidence does not lend strong support to the hypothesis that children drop subjects because of constraints on sentence length or on metrical structure. The convergence of evidence 
from different methodologies - that children omit subjects in elicited imitation, in spontaneous production, and also accept them in comprehension - strongly supports the hypothesis that omission is due to a common underlying system, the grammar.

It is, of course, still possible that that the grammatical option to omit subjects is determined under pressure from limited processing capacity, as proposed by Rizzi (2005b). The strongest support to date for processing effects in subject omission is the VP length result obtained by Bloom (1991) and Valian (1991, 1996). In the following section I will propose that VP length is in fact a pragmatic effect, as originally suggested in Hyams and Wexler (1993). Before returning to the VP length results, however, I first discuss the approach to argument realization that is assumed within most syntactic theories (since Chomsky 1982). I then provide a brief overview of studies that have investigated children's knowledge of the information structure principles that govern the distribution of null and overt arguments. As we will see, many of these studies replicate Hyams and Wexler's finding of a trade-off over time between null subject and overt pronouns, discussed above (Sect. 3.1), a result that is consistent with a modular grammatical/pragmatic account of subject omission, but at odds with a processing account.

\section{Information Structure and Null Subjects}

Grammatical accounts of null subjects are necessarily modular in structure (Chomsky 1982). The grammar (e.g. Italian, Chinese, etc.) allows the occurrence of a null element (pro, PRO, null topics and so on) under certain structural conditions of licensing and identification. But the syntax does not legislate when a particular subject will be omitted. This is a function of the information structure (IS) of the sentence, considerations such as the preceding discourse, situational context including speaker/hearer, the informational value of the subject, among other factors. ${ }^{28}$ All languages that permit argument omission, whether Italian-like pro drop languages, German-like topic drop, Chinese-like topic drop languages (Huang 1984), or mixed systems such as American Sign Language (Lillo-Martin 1994), have strict conditions on when the argument can, or must be omitted.

Conversely, discourse conditions alone cannot sanction missing arguments. For example, there is no discourse or situational factor that explains why languages require expletive subjects (e.g. 'it is raining, it seems that ....'), which are by definition void of informational content. ${ }^{29}$ This is a purely grammatical requirement. Moreover, there exist syntactic properties that covary with the NS phenomenon and which do not lend themselves to an obvious pragmatic explanation. For example,

\footnotetext{
${ }^{28}$ As pointed out by Sorace et al. (2009), pronoun realization also involves an understanding of the listener's mental state and perspective.

${ }^{29}$ My thanks to Tom Roeper for pointing this out.
} 
NS languages allow wh-extraction over a complementizer, as in Italian Chi pensi che _ sia partita? ('Who do you think that _ left?'), an extraction that is blocked in non-null subject languages, such as English. Indeed, one of the strongest pieces of evidence for a grammatical basis to null subjects comes from language development. Children acquiring Dutch, German, French and other non-null subject languages use far more null subjects with root infinitives than with finite verbs (see Hoekstra and Hyams (1998) for summary of statistics). Quite the contrary is predicted on informational grounds; children should be more likely to omit subjects when agreement features are specified on the verb. So the modular view of null arguments implicates both the grammar and information structure. In the next section I discuss the role of informational factors on children's NS use.

\subsection{Is Effects on Null Subjects in Child Language}

Early work on children missing subjects focused on the possible licensing mechanisms for null subjects in early grammar (e.g. pronominal Agr, morphological uniformity, etc.). And the empirical results reviewed above clearly support a grammatical model of early null subjects. But this does not exclude that children are sensitive to discourse factors and that these factors affect their use of null subjects, just as grammatical analyses of adult NS languages do not preempt the role of pragmatic factors in how null subjects are deployed. It is an empirical question to what extent children both those acquiring NS languages and also those acquiring languages in which the target is not a null subject or topic drop language - adhere to discourse conditions on argument omission.

The earliest work addressing these questions is Greenfield and Smith (1976) who attributed subject omission to a pragmatic tendency in children to drop old information, elements that are well established in discourse and/or non-linguistic context, and to produce those elements that provide new, focal information (possibly under pressure from an immature production system). Because subjects express old or given information more often than objects, they are frequently omitted while objects are not, giving rise to a subject-object asymmetry in argument drop. As Rizzi (2005b) observes, however, a purely informational account of this sort is at odds with the finding that in many languages, including German, French, Dutch, Flemish, children do not drop subjects in post- $w h$ contexts even though it is the $w h$-phrase that is focalized while the subject is old information..$^{30}$

More recently, a number of studies have investigated pragmatic/discourse effects in children acquiring null subject languages. Clancy $(1993,1997)$ shows that children acquiring Korean (age 1;8-2;10) are more likely to drop arguments that are more prominent in discourse (according to a range of features, including newness, contrast, query, absence, person and animacy) and express those arguments that are

\footnotetext{
${ }^{30}$ In English this restriction holds in finite wh-clauses (Roeper and Rohrbacher 2000 - see note 5).
} 
less prominent and hence less recoverable from context. Similarly, in a study of four Inuktitut-speaking children (aged 2;0-3;6), Allen (2000) shows the argument omission can be significantly predicted by the degree of 'informativeness' of an argument (as measured by several variables including newness, contrast, absence, differentiation in context, and person). Serratrice and Sorace (2003), using the same principles introduced by Clancy and Allen, also find significant discourse/pragmatic effects in the distribution of overt versus null subjects in six Italian-speaking children (ages 1;8 and 3;3), reflecting the distribution of the adult language. Serratrice and Sorace are explicit in assuming that the pragmatic principles operate within the boundaries imposed by the grammar, in this case a pro-drop grammar.

If children acquiring NS languages are sensitive to IS features governing argument realization, is the same true of subject drop in non-null subject grammars such as English? Guerriero et al. (2001) compare the effects of IS on the distribution of null, pronominal, and lexical subjects in the spontaneous speech of 3-year old Englishspeaking and Japanese-speaking children. They find that both groups of children tend to represent arguments that are new to discourse with lexical NPs and given arguments as either null or pronominal. They also find convergence with the adult targets in that Japanese children tend to omit arguments that represent given information while the English-speaking children pronominalize such arguments. Guerriero et al. note that the English-speaking children are old enough ( 3 years) to have exited the NS stage, and thus show an adult-like preference for pronouns over null arguments.

These results lead us to wonder what would happen if these children had been observed 6 months to a year earlier, while still in the NS stage. If the distribution of null, pronominal, and lexical arguments in NS languages has its basis in universal principles of information structure, as is generally assumed (e.g. Du Bois 1987; Guerriero et al. 2001, among others), and if young English-speaking children have a grammar that permits null subjects (e.g. a RSD grammar), we predict (a) that they would show a distribution of null and overt arguments similar to that of children acquiring 'real' NS languages, and (b) that there would be a trade-off over time between null arguments and pronouns, as Hyams and Wexler (1993) found. In other words, they would show continuity with respect to the discourse principles and the representation of new versus given information, but the grammatical representation of this information would shift over time from null to pronominal arguments as they move from a NS grammar to a non-NS grammar. This contrasts with a processing account (Bloom 1991; Valian 1991; Valian et al. 1996), which predicts a trade-off between null subjects and lexical NPs. ${ }^{31}$ Interestingly, Guerriero et al. (2001) note that a separate longitudinal study of English-speaking children that they conducted "nicely shows the developmental changes in which null forms become pronominal" (p. 328). Similarly, Hughes and Allen (2008), who investigate the role of discoursepragmatic information in the distribution of referential forms in 4-English-speaking children (aged 2;0-3;1), also find a trade-off over time between null subjects and pronouns. These results parallel those observed in Hyams and Wexler (1993).

\footnotetext{
${ }^{31}$ And which also do not predict any particular effect of discourse conditions.
} 
Hughes and Allen examine the effects of various 'accessibility features' (factors that render the referent of an NP more or less transparent), such as animacy, contextual disambiguation, physical presence, prior mention, linguistic disambiguation and joint attention. In addition to the trade-off between null subjects and pronouns, they also find that lexical forms decrease over time, which also contributes to the rise in pronouns. This result contrasts with Hyams and Wexler (1993), who found that NPs remain constant. The decrease in NPs is unexpected on an IS account as lexical NPs typically constitute new information, and therefore, unlike null subjects, which are presupposed, should not be replaced by pronouns. Hughes and Allen explain this result as an effect of motherese. They note that a prominent feature of child-directed language is the "overuse" of lexical NPs in cases where the referent is highly accessible, such as when the referent is either speaker or addressee, as illustrated in $(9 a, b)$ or has already been clearly established in discourse, as in $(9 d, e)$. (Examples are from Hughes and Allen). ${ }^{32}$

(9) a. MOT: Mommy doesn't want any sugar [mom about herself]

b. MOT: How old is Brian last week [speaking to child]

CHI: Brian got a big job to do.

d. $\mathrm{CH}$ : Butterfly has gone.

MOT: Where has the butterfly gone?

e. MOT: Where does the crocodile go.

$\mathrm{CH}$ : The crocodile go there.

Hughes and Allen suggest that redundant NPs in the input may be responsible for the higher than anticipated number of lexical NPs in highly accessible contexts in the children's language. These lexical forms are later replaced (appropriately) by pronouns as the motherese effect diminishes. ${ }^{33}$ Thus, the decrease in lexical NPs over time is very likely due to an independent motherese effect, and thus consistent with the hypothesis that English-speaking children initially use null subjects, and later pronouns, in discourse appropriate ways. ${ }^{34}$

Valian (1996) also finds that English-speaking children drop (or fail to imitate) pronouns more frequently than lexical NPs. Again, this is a direct consequence of the relative informational value of pronouns, which are redundant, and NPs, which introduce new information. Moreover, Valian (1996) and Hughes and Allen (2006)

\footnotetext{
${ }^{32}$ This phenomenon is also discussed in Hyams (2008) where I refer to examples such as (9a,b) as 'Mommy deixis'.

${ }^{33}$ Hughes and Allen (2008) also note that discourse/pragmatics effects are "cumulative" in that the degree of accessibility of a referent, as measured by the number of accessibility features it has, is also a factor in explaining the distribution of null, pronominal, and lexical forms. See their paper for details.

${ }^{34}$ The children studied by Hughes and Allen are somewhat older than the children studied by Hyams and Wexler (who looked at Adam and Eve's data, Childes, Brown 1973; MacWhinney and Snow 1985). It is possible that that the age differences are the source of the different results we found with respect to lexical NPsif children stop using lexical forms to refer to speaker/addressee (mommy deixis) at a somewhat older age.
} 
find that the rate of subject omission is substantially higher for 1st and 2nd person pronouns than for 3rd person, again an obvious contextual effect. This avoidance of pronouns is expected if the children's grammar licenses another option, namely the null subject option. According to Valian's measures, the children in her lower MLU group drop subjects and they are also the ones who show an 'avoid pronoun' strategy (Chomsky 1982). The higher MLU children, who have passed out of the NS stage, again by Valian's measures, imitate both pronouns and full NPs to the same degree. Finally, it is the lower MLU group that shows the VP length effect. This, I will suggest follows from pragmatic principles that can also be identified across adult NS languages. I turn to the VP length effect directly.

\subsection{An Information Structure Account of the VP Length Effect}

Hyams and Wexler (1993) suggested a pragmatic analysis of the VP length effect found in young English-speaking children (Bloom 1991). Our proposal was prompted by the finding that adult Italians also show this same result: VPs of null subject sentences tend to be longer than VPs in sentence with overt subjects, and there is also a difference in the predicted direction between sentences with pronominal subjects vs. lexical subjects.

Hyams and Wexler proposed that a VP in a NS language like Italian is more likely to contain new, focal information (hence be longer) when the subject is presupposed (i.e. null), while the use of a lexical NP subject signals new information (e.g. change of topic) and so will have a non-focalized (hence shorter) VP. In a NS language a pronoun subject is neither new information nor strictly presupposed, as it is used only when pragmatically warranted for contrast, disambiguation or emphasis and so on. Hence VP length in sentences with pronominal subjects falls somewhere in between. Although our proposal lacked much in the way of precision, there are some additional findings that lend plausibility to a pragmatic explanation of the VP length result. Du Bois $(1987,2003)$ observes that cross-linguistically, subjects of transitive verbs are associated with given information, and so show up as null or pronominal forms. Conversely, subjects of intransitive verbs and objects of transitive verbs are both associated with new information, and are therefore usually lexically realized. ${ }^{35}$ Assuming that children are sensitive to these principles (and various studies show that they are, as I will discuss below), the expectation is that children will drop subjects of transitive verbs more than subjects of intransitive verbs. This would clearly contribute to making the VPs of null subject sentences

\footnotetext{
${ }^{35}$ Du Bois (1987) explains this distribution in terms of 'informativeness' in the following way: because the subject of a transitive verb acts on the object or controls the events expressed by the verb, its presence is recoverable from the object which is acted upon (hence given). Intransitive verbs, on the other hand, denote events that are not controlled by the subject, rather the subject is affected, as is the object of a transitive verb and therefore, these arguments are not recoverable (hence $n e w$ ).
} 
(typically transitive) "longer" than the VPs of sentences with expressed subjects (typically intransitive) - not for processing reasons, but because of the information structure of the two types of VPs.

Indeed, Clancy (1993), Allen and Schroeder (2003) and Gürkanli et al. (2007) find that verb transitivity (as it relates to informativeness- see note 36) plays a role in argument realization in children acquiring Korean, Inuktitut, and Turkish (all NS languages); subjects of intransitives and objects of transitives tend to be lexically realized, while subjects of transitive verbs are omitted. Guerriero et al. (2001) find this same result for both their English and Japanese-speaking children. Thus, these studies all replicate Dubois' crosslinguistic finding for adults in children, consistent with the hypothesis that the VP length effect is a pragmatic one.

If VP length is a pragmatic effect and not a processing one, this would explain why Hyams and Wexler (1993) found the same result with adult Italian speakers. It would also clarify the seemingly contradictory results in Hamann and Plunkett's (1998) Danish-speaking children. Recall that they find that VP length decreases as a function of subject "heaviness" (null $>$ pronoun $>$ NP), but they also find that the MLUs for subjectless sentences are lower overall than for sentences with subjects, a result that they interpret to mean that, on average, processing resources do not determine subject omission.

\section{Some Concluding Remarks}

It would be misleading to suggest that children adhere perfectly to adult principles of information structure. Children do sometimes drop arguments when the referent is not easily accessible (Hughes and Allen 2008, among others). This may be partially responsible for the observation that children acquiring NS languages drop subjects more than adults (though, as noted earlier, there are conflicting findings in this regard). On the other hand, children may show a higher NS rate than adults because their language is more narrowly confined to the immediate discourse situation, and also because in adult-child interactions, it is typically adults who initiate topic changes (Serratrice 2005). These factors would inflate adult use of overt subjects relative to children's. If the latter speculation is correct, we would expect that as the child's discourse abilities develop such that she initiates more topic changes and is also less tightly tied to the immediate discourse situation, her NS rate will converge on that of the adult speaker. ${ }^{36}$

How the child acquiring a non-NS language such as English comes to match adult norms with respect to NS use, viz. diary drop is less clear. In Sect. 2.4, I considered two possible subject drop trajectories, one discontinuous, the other continuous.

\footnotetext{
${ }^{36}$ Hamann and Plunkett (1998) did not find an effect of discourse on subject omission in child Danish. However, as they acknowledge, they looked only at previous mention and not at any of the other IS variables that have been found to influence null subject use.
} 
A discontinuous trajectory would be consistent with a parametric shift (from RSD to non-RSD and then the learning of diary drop contexts by positive evidence). A continuous trajectory would instead be consistent with the idea that children maintain RSD into adulthood where it then manifests itself as 'diary drop'. In this instance there must be a developmental shift in the child's frame of reference (or discourse world) from a deictic one (based on immediate discourse/situational context) to a much stricter diary context. ${ }^{37}$ Exactly how that shift occurs is not obvious.

It seems clear that young children are more limited in their productive capacities than adults, due to shorter memory and attention spans, less planning capacity, and so on, Thus far, however, there is little compelling evidence that performance factors are sufficient to explain the missing subject phenomenon. Given the grammatical contingencies associated with null subjects, especially the interaction with finiteness and $w h$ questions, the most plausible explanation is that whatever production constraints exist, they operate within the parameters of the grammatical system, as proposed in Rizzi (2005a, b).

However, a mixed processing-competence account is supported only to the extent that there is indeed evidence pointing to specific performance effects on subject omission. The strongest evidence to date is the VP length effect (Bloom 1970, 1991). Hyams and Wexler (1993) replicate this result in Italian adults, making a processing explanation unlikely. Moreover, various studies of both adults and children have shown that new information is more often represented in subject of transitive verbs (Du Bois 1987, 2003; Clancy 1993; Allen and Schroeder 2003; Gürkanli et al. 2007). This would mimic the VP length effect, but for pragmatic reasons, as suggested in Hyams and Wexler, without recourse to processing constraints in children that are neither well understood nor precisely formulated.

There is now substantial evidence from children acquiring null subject languages of different types that general principles of information structure influence the distribution of null and overt subjects in languages where argument omission is a grammatical option. However, such principles alone cannot license null arguments in languages in which this is not a grammatical option. Rather, the IS principles operate within the constraints of the grammatical system.

There is also increasing evidence that English-speaking children are sensitive to such informational principles, first with respect to null subjects and then with respect to the (almost) functionally equivalent pronouns that eventually supplant null arguments. This array of pragmatic data lends additional support to the hypothesis that null subjects are a grammatical, and likely parametric option for young children.

Various parameter setting models of the NS phenomenon have been proposed over the years, some suggesting a fixed initial setting, others multiple, competing settings.

\footnotetext{
${ }^{37}$ In Hyams (1996) I suggest that children drop pronouns, determiners and tense (during the RI stage) because they have an option to interpret these functions deictically, that is, through situational anchoring. This idea is further developed in Hyams (2007) where I look at the interpretations associated with different non-finite verbs (e.g. RIs, bare participles, bare verbs, etc.) in various child languages.
} 
There are also different analyses of how parameter resetting is determined - maturation, processing load, or statistical factors, or some combination of these. There is a range of empirical findings many of which are handled by one or the other of these accounts, but it does not seem that any one account covers the full range of facts. Also, some of the empirical predictions made by the various hypotheses discussed in this overview have yet to be tested in detail. I think it is fair to say that the jury is still out on the correct analysis of early null subjects, but it is clear that the phenomenon is vastly more complex than was initially assumed.

Acknowledgments I would like to thank Robyn Orfitelli and Kamil Ud Deen for their helpful comments on an earlier draft of this paper. I am grateful also to Jill de Villiers and Tom Roeper for inviting me to contribute to this volume, and for carefully reading and critiquing this paper.

\section{References}

Allen, S. 2000. A discourse-pragmatic explanation for argument representation in child Inuktitut. Linguistics 38(3): 483-521.

Allen, S., and H. Schroeder. 2003. Preferred argument structure in early Inuktitut spontaneous speech data. In Preferred argument structure: Grammar as architecture for function, ed. J. Du Bois, L. Kumpf, and W. Ashby, 301-338. Amsterdam: Benjamins.

Babyonyshev, M. 1993. Acquisition of the Russian case system. In Papers on case \& agreement II, ed. C. Phillips. MIT Working Papers in Linguistics 19: 1-43.

Bates, E. 1976. Language and context: The acquisition of pragmatics. New York: Academic.

Bel, A. 2003. The syntax of subjects in the acquisition of Spanish and Catalan. Probus: International Journal of Latin and Romance Linguistics 15(81): 1-26.

Berwick, R.C. 1982. Locality principles and the acquisition of syntactic knowledge. $\mathrm{PhD}$ diss., MIT, Department of Computer Science, Cambridge, MA.

Bloom, L. 1970. Language development: Form and function in emerging grammars. Cambridge, MA: MIT Press.

Bloom, P. 1991. Subjectless sentences in child language. Linguistic Inquiry 21: 491-504.

Bloom, L., P. Lightbown, and L. Hood. 1975a. Structure and variation in child language. Monographs of the Society for Research in Child Development 40(2): 1-79.

Bloom, L., P. Miller, and L. Hood. 1975b. Variation and reduction as aspects of competence in language development. In Millllesota symposia 011 child psychology, vol. 9, ed. A. Pick, 3-55. Minneapolis: University of Minnesota Press.

Borer, H., and K. Wexler. 1987. The maturation of syntax. In Parameter setting, ed. T. Roeper and E. Williams, 123-172. Dordrecht: Reidel.

Borer, H., and K. Wexler. 1992. Bi-unique relations and the maturation of grammatical principles. Natural Linguistics and Linguistic Theory 10: 147-189.

Bromberg, H., and K. Wexler. 1995. Null subjects in Wh questions. MIT WPL 26: 221-248.

Brown, R. 1973. A first language. Cambridge, MA: Harvard University Press.

Brown, R., and C. Fraser. 1964. The acquisition of syntax. In The acquisition of language, ed. U. Bellugi and R. Brown, 43-78. Chicago: University of Chicago Press.

Brown, R., C. Fraser, and U. Bellugi. 1964. Explorations in grammar evaluation. In The acquisition of language, ed. U. Bellugi and R. Brown, 79-91. Chicago: University of Chicago Press.

Cabré Sans, Y., and Gavarró, A. 2006. Subject distribution and verb classes in child Catalan. In Proceedings of the 2nd Conference of GALANA, 51-60. Somerville: Cascadilla Press.

Chomsky, N. 1965. Aspects of the theory of syntax. Cambridge, MA: MIT Press. 
Chomksy, N. 1977. On Wh movement. In Formal Syntax, eds. P. Culicover, P. T. Wasow, and A. Akmajian, New York: Academic Press.

Chomsky, N. 1982. Some concepts and consequences of the theory of government and binding. Cambridge, MA: MIT Press.

Clahsen, H., S. Eisenbeiss, and M. Penke. 1994. Lexical learning and early syntactic development. In Language learning and language disorders, ed. H. Clahsen. Amsterdam: John Benjamins Publishing Co.

Clahsen, H., C. Kursawe, and M. Penke. 1995. Introducing CP: Wh-questions and subordinate clauses in German child language. Essex Research Reports in Linguistics 7: 1-28. Essex: University of Essex, Department of Linguistics.

Clancy, P. 1993. Preferred argument structure in Korean acquisition. In Proceedings of the 25th Annual Child Language Research Forum, ed. E. Clark, 307-314. Stanford: CSLI.

Clancy, P. 1997. Discourse motivations of referential choice in Korean acquisition. In Japanese/ Korean linguistics, vol. 6, ed. H. Sohn and J. Haig, 639-659. Stanford: CSLI.

Clark, R., and I. Roberts. 1991. A computational model of language learnability and language change. Unpublished manuscript, Geneva: University of Geneva.

Crain, S., and C. McKee. 1985. The acquisition of structural restrictions on anaphora. In Proceedings of NELS 15, 94-110. Amherst: University of Massachusetts, GLSA.

Crisma, P. 1992. On the acquisition of wh-questions in French. GenGenP, 115-122. Geneva: University of Geneva.

Crousaz, D., and U. Schlonsky. 2003. The distribution of a subject clitic pronoun in a FrancoProvençal dialect. Linguistic Inquiry 34: 413-442.

de Haan, G., and K. Tuijman. 1988. Missing subjects and objects in child grammar. In Language development, ed. P. Jordens and J. Lalleman, 101-122. Dordrecht: Foris.

den Besten, Hans. 1977/1983. On the interaction of root transformations and lexial deletive rules. In On the formal syntax of Westgermania, ed. W. Abraham, 7-131. Amsterdam: J. Behjamins.

Drozd, K. 1995. Child English pre-sentential negation as metalinguistic exclamatory sentence negation. Journal of Child Language 22: 583-610.

Du Bois, J. 1987. The discourse basis of ergativity. Language 63: 805-855.

Du Bois, J. 2003. Argument structure: Grammar in use. In Preferred argument structure: Grammar as architecture for function, ed. J. Du Bois, L. Kumpf, and W. Ashby, 81-108. Amsterdam: Benjamins.

Ervin-Tripp, S. 1964. Imitation and structural change in children's language. In New directions in the study of language, ed. E. Lenneberg. Cambridge, MA: MIT Press.

Felix, S. 1987. Cognition and language growth. Dordrecht: Foris.

Fodor, J.D. 1998. Unambiguous triggers. Linguistic Inquiry 29: 1-36.

Gerken, L. 1991. The metrical basis for children's subjectless sentences. Journal of Memory and Language 30(4): 431-451.

Gerken, L. 1994. Young children's representation of prosodic phonology: Evidence from Englishspeakers' weak syllable productions. Journal of Memory and Language 33(1): 19-38.

Gibson, E., and K. Wexler. 1994. Triggers. Linguistic Inquiry 25(3): 407-454.

Greenfield, P., and J. Smith. 1976. The structure of communication in early language development. New York: Academic.

Guasti, M.-T. 1993/1994. Verb syntax in Italian child grammar: Finite and non-finite verbs. Language Acquisition 3(1): 1-40.

Guasti, T. 1996. The acquisition of Italian interrogatives. In Generative perspectives on language acquisition, ed. H. Clahsen, 241-270. Amsterdam: Benjamins.

Guerriero, A., A. Cooper, Y. Oshima-Takane, and Y. Kuriyama. 2001. A discourse-pragmatic explanation for argument realization and omission in English and Japanese children's speech. In Proceedings of the 25th Annual BUCLD, vol. 1, 319-330. Somerville: Cascadilla Press.

Guilfoyle, E. 1984. The acquisition of tense and the emergence of lexical subjects. McGill Working Papers in Linguistics. McGill University, Montreal, Canada.

Gürkanli, O., M. Nakupoglu, and A. Özyürek. 2007. Shared information and zrgument omission in Turkish. In Proceedings of the 31st Annual BUCLD, vol. 2, 262-273. Somerville: Cascadilla Press. 
Haegeman, L. 1990. Non-overt subjects in diary contexts. In Grammar in progress, ed. J. Mascaro and M. Nespor, 167-179. Dordrecht: Foris.

Haegeman, L. 1992. Generative syntax: Theory and description. A case study of West Flemish. Cambridge: CUP.

Haegeman, L. 1994. Root infinitives, tense and truncated structures. Language Acquisition 4(3): 205-255.

Haegeman, L. 1995. Root null subjects and root infinitives in early Dutch. In Proceedings of the GALA 1995, ed. C. Koster and F. Wijnen. Groningen: Center for Language and Cognition.

Haegeman, L. 1996. Root infinitives, clitics and truncated structures. In Generative perspectives on language acquisition, ed. H. Clahsen, 271-309. Amsterdam: Benjamins.

Haegeman, L. 2000. Adult null subjects in non pro-drop languages. In The acquisition of syntax, ed. M.A. Friedman and L. Rizzi, 329-346. Harlow: Longman.

Hamann, C. 1996. Null arguments in German child language. Language Acquisition 5: $155-208$.

Hamann, C. 2000. The acquisition of constituent questions and the requirements of interpretation. In The acquisition of syntax, ed. M. Friedemann and L. Rizzi, 190-201. Harlow: Longman.

Hamann, C., and K. Plunkett. 1998. Subjectless sentences in child Danish. Cognition 69: 35-72.

Hamann, C., L. Rizzi, and U. Frauenfelder. 1996. The acquisition of subject and object clitics in French. In Generative perspectives on acquisition, ed. H. Clahsen, 309-334. Amsterdam: Benjamins.

Hoekstra, T., and N. Hyams. 1998. Aspects of root infinitives. Lingua 106: 81-112.

Huang, C.-T.J. 1984. On the distribution and reference of empty pronouns. Linguistic Inquiry 15: 531-574.

Hughes, M., and S. Allen. 2006. A discourse-pragmatic analysis of subject omission in child English. In Proceedings of the 30th Annual BUCLD, vol. 1, 293-304. Somerville: Cascadilla Press.

Hughes, M., and S. Allen. 2008. Child-directed speech and the development of referential choice in child English. Talk presented at the International Association for the Study of Child Language Conference, Edinburgh, Scotland.

Hyams, N. 1983. The acquisition of parameterized grammars. PhD diss., MIT Department of Linguistics, Cambridge, MA.

Hyams, N. 1986. Language acquisition and the theory of parameters. Dordrecht: Reidel.

Hyams, N. 1991. A reanalysis of null subjects in child language. In Theoretical issues in language acquisiton, ed. J. Weissenborn, H. Goodluck, and T. Roeper. New Jersey: Lawrence Erlbaum Associates, Inc.

Hyams, N. 1992. The genesis of clausal structure. In The acquisition of verb placement; functional categories and V2 phenomena in language development, ed. J. Meisel, 371-400. Dordrecht: Kluwer.

Hyams, N. 1994. V2, null arguments and C projections. In Language acquisition studies in generative grammar, ed. T. Hoekstra and B. Schwartz, 1-55. Philadelphia: Benjamins.

Hyams, N. 1996. The underspecification of functional categories in early grammar. In Generative Perspectives on Language Acquisition, ed. H. Clahsen. John Benjamins: Amsterdam.

Hyams, N. 2007. Aspectual effects on interpretation. Language Acquisition 14(3): 231-268.

Hyams, N. 2008. Reflections on Motherese. In An Enterprise in the Cognitve Science of Language, eds. T. Sano, M. Endo, M. Isobe, K. Otaki, K. Sugisaki, and T. Suzuki, 1-12. Tokyo: Hituzi Syobe Publishing.

Hyams, N., and O. Jaeggli. 1986. Null subjects and morphological development in child language. Unpublished manuscript.

Hyams, N., and K. Wexler. 1993. On the grammatical basis of null subjects in child language. Linguistic Inquiry 24(3): 421-459.

Ingham, R. 1998. Tense without agreement in early clause structures. Language Acquisition 7: $51-81$.

Jaeggli, O. and N. Hyams. 1988. Morphological uniformity and the setting of the null subject parameter. In Proceedings of the NELS 18, 239-253. University of Massachusetts, Amherst: GLSA. 
Jaeggli, O., and K. Safir. 1989. The null subject parameter and parametric theory. In The null subject parameter, ed. O. Jaeggli and K. Safir, 1-44. Dordrecht: Kluwer.

Jakubowicz, C., N. Müller, B. Riemer, and C. Rigaut. 1996. The case of subject and object omission in French and German. In Proceedings of the 21st Annual BUCLD, vol. 1, 331-342. Somerville: Cascadilla Press.

Kenstowicz, M. 1989. The null subject parameter in modern Arabic dialects. In The null subject parameter, ed. O. Jaeggli and K. Safir, 263-342. Dordrecht: Kluwer.

Kim, Y.-J. 1997. The acquisition of Korean. In The cross-linguistic study of language acquisition, vol. 4, ed. D.I. Slobin, 335-435. Hillsdale: Lawrence Erlbaum.

Klein, S.M. 1982. Syntactic theory and the developing grammar: reestablishing the relationship between linguistic theory and data from language acquisition. PhD diss., UCLA, Los Angeles, California.

Klima, E., and U. Bellugi. 1966. Syntactic regularities in the speech of children. In Psycholinguistic papers, ed. J. Lyons and R. Wales, 183-208. Edinburgh: Edinburgh University Press.

Koster, J. 2003. All languages are Tense second. In Germania et alia: A linguistics Webschrift for Hans den Besten, eds. J. Koster and Henk van Riemdijk: www.let.rug.nl/ koster/DenBesten/ Koster.pdf.

Kramer, I. 1993. The licensing of subjects in early child language. MIT WPL 19, 197-212

Lebeaux, D. 1987. Comments on Hyams. In Parameter setting, ed. T. Roeper and E. Williams, 23-39. Dordrecht: Foris.

Levow, G. 1995. Tense and subject position in interrogatives and negatives in child French. MIT WPL 26, 281-304.

Lillo-Martin, D. 1994. Setting the null argument parameters: Evidence from American sign language. In Syntactic theory and first language acquisition: Cross-linguistic perspectives. Vol. 2, Binding, Dependencies, and Learnability, ed. B. Lust, G. Hermon, and J. Kornfilt, 301-318. Hillsdale: Lawrence Erlbaum.

Lorusso, P. 2007. The acquisition of aspect in L1 Italian. In Proceedings of the 2nd Conference of GALANA, 253-264. Somerville: Cascadilla Press.

Lorusso, P., C. Coprin, and M. T. Guasti. 2004. Overt subject distribution in early Italian children. Online. Available: http://www.bu.edu/linguistics/APPLIED/BUCLD/supp29.html.

Lust, B., L. Solan, S. Flynn, C. Cross, and E. Schuetz. 1986. A comparison of null and pronoun anaphora in first language acquisition. In Studies in the acquisition of anaphora. Vol. I, Defining the Constraints, ed. B. Lust, 245-278. Dordrecht: Reidel.

Lust, B., Y. Chien, and S. Flynn. 1987. What children know: Methods for the study of first language acquisition. In Studies in the acquisition of anaphora. Vol. II, Applying the constraints, ed. B. Lust, 271-356. Dordrecht: Reidel.

MacWhinney, B., and C. Snow. 1985. The child language data exchange system. Journal of Child Language 12: 271-296.

O'Grady, W., A.M. Peters, and D. Masterson. 1989. The transition from optional to require subjects. Journal of Child Language 16: 513-529.

Orfitelli, R. 2008. Null subjects in child language: The competing roles of competence and performance. Master's thesis, UCLA, Los Angeles, California.

Orfitelli, R., and N. Hyams. 2008. An experimental study of children's comprehension of null subjects: Implications for grammatical/performance accounts. In Proceedings of the 32nd Annual BUCLD, vol. 2, 335-346. Somerville: Cascadilla Press.

Orfitelli, R., and N. Hyams. 2010. Null subjects in child language: The competing roles of competence and performance. UCLA manuscript, Los Angeles, California.

Phillips, C. 1995. Syntax at age 2. Crosslinguistic differences. MIT WPL 26, 325-382.

Pierce, A. 1992. Language acquisition and syntactic theory: A comparative analysis of French and English child grammars. Dordrecht: Kluwer.

Pinker, S. 1984. Language learnability and language development. Cambridge, MA: Harvard University Press.

Poeppel, D., and K. Wexler. 1993. The full competence hypothesis of clause structure. Language 69(1): 1-33. 
Radford, A. 1990. Syntactic theory and the acquisition of English syntax. Cambridge, MA: Blackwell.

Rasetti, L., M. Friedemann, and L. Rizzi. 2000. Null subjects and root infinitives in child grammar of French. In The acquisition of syntax, 236-268. Harlow: Longman.

Rizzi, L. 1982. Issues in italian syntax. Dordrecht: Foris.

Rizzi, L. 1993/1994. Some notes on linguistic theory and language development: The case of root infinitives. Language Acquisition 3: 371-393.

Rizzi, L. 2000. Remarks on early null subjects. In The acquisition of syntax, ed. M. Friedemann and L. Rizzi, 269-292. Harlow: Longman.

Rizzi, L. 2005a. On the grammatical basis of language development: A case study. In The Oxford handbook of comparative syntax, ed. G. Cinque and R. Kayne, 70-109. New York: Oxford University Press.

Rizzi, L. 2005b. Grammatically-based target-inconsistencies in child language. In Proceedings of the Inaugural Conference of GALANA. Cambridge, MA: UCONN/MIT Working papers in Linguistics.

Roeper, T. 2000. Universal bilingualism. Bilingual Language Cognition 2: 169-186.

Roeper, T., and B. Rohrbacher. 2000. True Pro-drop in child English and the principle of economy or projection. In The acquisition of scrambling and cliticization, eds. S. Powers and C. Hamann, 345-396. Dordrecht: Kluwer.

Roeper, T., and J. Weissenborn. 1990. How to make parameters work: Comments on Valian. In Language processing and language acquisition, ed. L. Frazier and J. de Villiers, 147-162. Dordrecht: Kluwer.

Sano T. and Hyams, N. 1994. Agreement, finiteness, and the development of null arguments. In Acquisition of scrambling and cliticization, eds. S. Powers and C. Hamann, 345-396. Dordrecht: Kluwer. Proceedings of NELS 24, ed. M. Gonzales, 543-548. University of Massachusetts, Amherst: GLSA.

Schütze, C. 1996. Evidence of case-related functional projections in early German. In The Proceedings of the Fourteenth West Coast Conference on Formal Linguistics, 447-462. Stanford: CSLI.

Serratrice, L. 2005. The role of discourse pragmatics in the acquisition of subjects in Italian. Applied Psycholinguistics 26: 437-462.

Serratrice, L., and A. Sorace. 2003. Overt and null subjects in Monolingual and Bilingual Italian acquisition. In Proceedings of the 27th Annual BUCLD, vol. 2, 739-750. Somerville: Cascadilla Press.

Sorace, A., L. Serratrice, F. Filaci, and M. Baldo. 2009. Discourse conditions on subject pronoun realization: Testing the linguistic intuitions of older bilingual children. Lingua 119: 460-477.

Stromswold, K. 1990. Learnability and the acquisition of auxiliaries. MIT PhD diss.

Thrasher, R. 1977. One way to say more by saying less. A study of so-called subjectless sentences. Kwansei Gakuin University Monograph Series, vol. 11. Tokyo: The Eihosha Ltd.

Tyack, D., and D. Ingram. 1977. Children's production and comprehension of questions. Journal of Child Language 4: 211-224.

Valian, V. 1990. A problem for parameter-setting models of language acquisition. Cognition 35(2): 105-122.

Valian, V. 1991. Syntactic subjects in the early speech of American and Italian children. Cognition 40: 21-81.

Valian, V., and Z. Eisenberg. 1996. Syntactic subjects in the spontaneous speech of Portuguesespeaking children. Journal of Child Language 23: 103-128.

Valian, V., J. Hoeffner, and S. Aubry. 1996. Young children's imitation of sentence subjects: Evidence of processing limitations. Developmental Psychology 32(1): 153-164.

Verrips, M., and J. Weissenborn. 1992. Routes to verb placement in early German and French. The independence of finiteness and agreement. In The acquisition of verb placement. Functional categories and V2 phenomena in language acquisition, ed. J. Meisel, 283-331. Dordrecht: Kluwer.

Wang, Q., D. Lillo-Martin, C. Best, and A. Levitt. 1992. Null subject versus null object: Some evidence from the acquisition of Chinese and English. Language Acquisition 2: 221-254. 
Weverink, M. 1989. The subject in relation to inflection in child language. MA thesis, University of Utrecht, The Netherlands.

Wexler, K. 1994. Optional infinitives, head movement and economy of derivation. In Verb movement, ed. N. Hornstein and D. Lightfoot. Cambridge: Cambridge University Press.

Wexler, K. 1998. Very early parameter setting and the unique checking constraint: A new explanation of the optional infinitive stage. Lingua 106(1-4): 23-79.

Wexler, K., and P. Culicover. 1980. Formal principles of language acquisition. Cambridge, MA: MIT Press.

White, L. 1981. Grammatical theory and language acquisition. PhD diss., McGill University, Montreal, Canada.

Yang, C. 2002. Knowledge and learning in natural language. Oxford: Oxford University Press. 